\title{
Participação e pós-materialismo na América Latina
}

\author{
Ednaldo Ribeiro \\ Departamento de Ciências Sociais \\ Universidade Estadual de Maringá \\ Julian Borba \\ Departamento de Sociologia e Ciência Política \\ Universidade Federal de Santa Catarina
}

\begin{abstract}
Resumo: 0 artigo procura testar no nível individual e para um grupo de quatro países latinoamericanos a hipótese proposta pelos defensores da teoria do desenvolvimento humano sobre a associação entre valores pós-materialistas e uma postura participativa. Utilizando dados produzidos pela Pesquisa Mundial de Valores procuramos verificar em que medida essa afirmação é pertinente no contexto de nações com questões materiais e economicas não resolvidas e caracterizadas como jovens democracias. Através de técnicas de análise bivariada e multivariada constatamos que entre os públicos desses países a participação é mais influenciada por variáveis relacionadas à centralidade social dos cidadãos do que por mudanças nas suas prioridades valorativas, o que leva à conclusão de que a transposição do modelo explicativo sugerido por Inglehart para o cenário latinoamericano é problemática e deve ser avaliada criticamente.
\end{abstract}

Palavras-chave: participação, valores, pós-materialismo, democracia, cultura política

Abstract: The article tests at the individual level and for a group of four Latinamerican countries the hypothesis proposed by the defenders of the theory of the human development about the association between postmaterialist values and a participative posture. Using data from the World Values Survey we verify the validity of this in that measured that statement in the context of nations with economics and materials problems and characterized as young democracies. Using techniques of bivariate and multivariate analysis we verifyed that among publics of those countries the participation is more influenced by variables related to the citizens' social centrality than by changes in their value's priorities, what leads to the conclusion that the explanatory model suggested by Inglehart is problematic to Latinamerica contexts and should be criticized.

Keywords: participation, values, post-materialism, democracy, political culture

OPINIÃO PÚBLICA, Campinas, vol. 16, no 1, Junho, 2010, p. 28-63 


\section{Introdução $^{1}$}

O livro The Silent Revolution, publicado por Ronald Inglehart no final da década de 1970 é apontado como obra inaugural de um programa de investigações que afirmam a ocorrência de uma lenta e contínua alteração nas prioridades valorativas individuais em nível mundial. Passadas quase três décadas de pesquisas empíricas e teóricas, a tese da mudança de um amplo conjunto de valores humanos em direção a uma postura pós-materialista continua sendo testada dezenas de países nas diferentes regiões do globo.

Pesquisadores do tema têm afirmado que, apesar das significativas diferenças culturais entre as várias nações estudadas, essa reorientação valorativa resultava principalmente do desenvolvimento econômico experimentado a partir da segunda metade do século $X X$, especialmente pelas sociedades industriais avançadas (INGLEHART, 1977; 1990; 2001; INGLEHART \& WELZEL, 2005).

Tal fenômeno cultural teria conseqüências para os mais variados campos: da organização do trabalho às relações de gênero, do comportamento sexual à religiosidade. Na dimensão política teria efeito bastante positivo sobre os processos de democratização, pois estaria associado à adoção de valores e atitudes congruentes com essa forma de governo (INGLEHART \& WELZEL, 2005). Ainda que pareça paradoxal à primeira vista, tais orientações subjetivas também seriam acompanhadas de uma postura crítica em relação ao funcionamento das instituições políticas e, sobretudo, pelo questionamento dos mecanismos tradicionais de representação (INGLEHART, 1990; 2001; INGLEHART \& WELZEL, 2005). O reflexo dessa atitude crítica seria a redução significativa nas taxas de mobilização política convencional verificada nas últimas décadas nas sociedades industriais avançadas. A contradição, todavia, seria apenas aparente. Esse quadro não seria um sinal de apatia por parte dos públicos dessas nações, pois em paralelo à redução na participação tradicional estaria ocorrendo processo inverso nas chamadas elite-directed political action, ou seja, nas atividades de contestação às instituições e elites estabelecidas (NORRIS, 2002; INGLEHART \& WELZEL, 2005).

Uma vez superados os limites estritos da sobrevivência material e econômica, os indivíduos estariam se preocupando cada vez mais com questões relacionadas à sua auto-expressão, gerando uma "intervenção cidadã na política" (INGLEHART, 2001, p. 221). O desejo de tomar parte dos assuntos públicos de uma maneira mais ativa e direta acompanharia, portanto, a mudança pós-materialista.

\footnotetext{
${ }^{1}$ Esse trabalho é resultado da pesquisa "Participação e Pós-materialismo na América Latina", coordenada pelo professor Ednaldo Ap. Ribeiro e financiada pela Secretaria de Estado da Tecnologia, Ciência e Ensino Superior do Paraná/Fundação Araucária. Agradecemos as observações críticas e sugestões dos pareceristas anônimos da Opinião Pública.
} 
Evidências empíricas robustas têm sido apresentadas desde o final da década de 1970 para confirmar esses argumentos no nível individual (BARNES et al, 1979; INGLEHART, 1999; NORRIS, 2002). Em perspectiva mundial os valores pós-materialistas estariam fortemente associados a ações políticas nãoconvencionais, como manifestações, boicotes, ocupações, bem como ao interesse por política em geral.

Nesse artigo procuramos verificar se algo semelhante ocorre quando contextos regionais particulares são focalizados, sobretudo quando esses apresentam configurações socioeconômicas significativamente distintas das existentes nas sociedades de industrialização avançada. Tentando contribuir para essa discussão, nos concentramos sobre o caso latinoamericano, buscando verificar se entre os públicos dessas nações também se verifica a associação entre a priorização de objetivos pós-materialistas e um conjunto de valores e atitudes relacionados ao tema da participação política.

Cabe alertar desde já que nossa análise se concentra especificamente sobre esse nível individual. As nações incluídas em nossas análises obviamente não fazem parte do restrito grupo das nações pós-industriais e suas histórias econômicas apresentam, com algumas particularidades, processos de modernização incompletos e frágeis em diferentes aspectos. Conseqüentemente, exibem contingentes bastante reduzidos de pós-materialistas na comparação com nações economicamente desenvolvidas e que são os alvos principais dos pesquisadores da mudança cultural. Isso, entretanto, não inviabiliza análises que se debruçam sobre os efeitos individuais dessa alteração nas prioridades valorativas. Gibson e Duch (1994), por exemplo, realizam interessante investigação sobre o efeito da adesão aos valores pós-materialistas sobre a cultura política dos cidadãos de ex-repúblicas soviéticas mesmo considerando que o total de indivíduos pós-materialistas não chegava $10 \%$ da população. Opp (1990) faz algo semelhante em estudo sobre a então Alemanha Ocidental. Ribeiro (2008) estuda o impacto desses valores sobre um amplo espectro de variáveis relativas à cultura política dos cidadãos brasileiros, ainda que os materialistas representem a maioria absoluta desse público. Os dois primeiros são inclusive citados por Inglehart e Welzel (2005) como exemplos de pesquisas que confirmam suas teses para contextos econômicos em desenvolvimento e no nível micro.

Desta forma, ainda que os países latinoamericanos não apresentem as condições necessárias à configuração da síndrome pós-materialista, é legítima a análise dos impactos individuais da adoção dessas prioridades por parte das suas populações sobre diferentes dimensões das suas atitudes e comportamentos políticos. Acreditamos que tal questionamento seja pertinente, pois as particularidades da cultura política latinoamericana, as baixas taxas de mobilização aqui verificadas e a elevada desigualdade que afeta essas nações podem 
representar elementos relevantes para a discussão das teses propostas por Inglehart e seus colaboradores em nível mundial.

\section{Medidas de pós-materialismo e estratégias metodológicas}

Utilizamos os dados produzidos pela última onda conduzida pelo projeto World Values Surveys (WVS) ${ }^{2}$, concluída em 2006. O WVS é uma grande investigação sobre mudanças sócio-culturais e políticas, executada por uma rede global de cientistas sociais a partir de surveys aplicados a amostras nacionais representativas de mais de 80 nações espalhadas por todos os continentes. As coletas de dados têm se repetido desde o início da década de 1980 em sucessivas ondas (1980-1984, 1990-1993, 1995-1997, 1999-2002 e 2005-2008) e, na sua última edição concluída, produziu dados representativos para mais de $80 \%$ da população mundial. No presente trabalho nos valemos dos dados de Argentina, Brasil, Chile e Peru. ${ }^{3}$ Apesar de bastante abrangente em suas dimensões o WVS não consegue em todas as suas ondas envolver a totalidade dos países de algumas regiões. Esse é o caso da América Latina, na qual apenas sete países foram incluídos na rodada de 2005-2008. Além dos selecionados para nossa pesquisa estão disponíveis apenas os dados para Colômbia, México e Uruguai. Desta forma, a seleção levou em consideração primeiramente a disponibilidade de informações, ainda que algumas nações, por diferentes razões, merecessem nossa atenção. Um segundo problema relevante diz respeito a algumas diferenças no instrumento de coleta de dados e no seu processo de tabulação. Apesar do WVS gerar informações úteis para a comparação entre países e também para a identificação de tendências em indicadores ao longo do tempo, nem sempre as mesmas perguntas são formuladas a todos os públicos e algumas questões sofrem alterações de uma onda para outra. Desta forma, fomos obrigados a selecionar casos cujas variáveis e indicadores possuam semelhanças suficientes para viabilizar a análise integrada e comparada dos dados. Foi seguindo essa lógica que, partindo dos sete países iniciais, realizamos sucessivas exclusões até chegarmos aos quatro países já apontados.

\footnotetext{
2 Essa base está disponível no endereço <http://www.worldvaluessurvey.org/>. Aproveitamos a oportunidade para agradecer a Ronald Inglehart, presidente do WVS, por permitir o acesso aos dados. $3 \mathrm{Na}$ Argentina, a coleta de dados foi conduzida pelo instituto TNS Gallup Argentina entre os dias 20/06 e 24/07/2006, com amostra de 1002 indivíduos. No Brasil a Universidade de Brasília foi responsável pela aplicação dos questionários a uma amostra de 1500 pessoas entre os dias 01/11 e 26/12/2006. No Chile, a coleta foi conduzida por Mori Market Opinion Research Internacional junto a uma amostra de 1000 indivíduos entre os dias 14/06 e 24/07/2006. Por fim, no Peru, a condução ficou a cargo do Instituto de Opinión Pública de la PUC que entrevistou 1500 pessoas entre os dias 07 e 15/12/2006. Informações técnicas adicionais sobre os procedimentos amostrais podem ser obtidos no site mencionado na nota anterior.
} 
O índice de materialismo/pós-materialismo desenvolvido por Inglehart (1990) é utilizado como medida de adesão aos valores pós-materialistas em todos os testes e análises que apresentamos. O índice é obtido através da aplicação de uma bateria composta por 12 itens que representariam os principais objetivos prioritários de qualquer sociedade, a saber: 1) manter a ordem, 2) aumentar a participação dos cidadãos nas decisões importantes, 3) combater o aumento de preços 4) proteger a liberdade de expressão, 5) manter altas taxas de crescimento econômico, 6) assegurar que o país tenha importantes forças de defesa, 7) dar maior importância à opinião das pessoas sobre os assuntos em seu trabalho e comunidade, 8) fazer das cidades e paisagens mais bonitas, 9) manter a economia estável, 10) progredir em direção a uma sociedade menos impessoal e mais humana, 11) lutar contra a delinqüência e 12) progredir em direção a uma sociedade onde as ideias são mais importantes que o dinheiro.

A partir das prioridades selecionadas, os indivíduos são dispostos em uma escala de 6 pontos, na qual " 0 " corresponde a uma posição radicalmente materialista e " 5 " a uma postura pós-materialista extremada".

As variáveis relacionadas aos valores e atitudes participativas e também os procedimentos empregados na construção de alguns índices propostos por nós são apresentados ao longo da exposição e discussão dos resultados ${ }^{5}$.

\section{Pós-materialismo e desenvolvimento}

Como afirmamos anteriormente, nosso foco nesta pesquisa recai sobre as hipóteses derivadas da teoria do desenvolvimento humano (INGLEHART \& WELZEL, 2005) para o nível individual, mas ainda assim um breve esforço de enquadramento das nações selecionadas para o estudo no quadro mais geral da mudança cultural

\footnotetext{
4 Para detalhes do índice, consultar Inglehart (1990).

5 A análise dos dados que apresentamos a seguir busca principalmente verificar a existência e a intensidade da associação entre índices e variáveis. Para tanto, com o emprego do software SPSS 13.0 for Windows, o procedimento estatístico inicialmente utilizado foi o cruzamento entre o índice de materialismo/pós-materialismo mencionado e alguns indicadores disponibilizados pelo WVS sobre os valores e atitudes relativos à participação política.

Para verificar a existência da associação entre as variáveis envolvidas nos cruzamentos optamos pelo coeficiente $\gamma$ (Gamma) de Goodman e Kruskal, útil nos casos em que as variáveis são qualitativas e medidas no nível ordinal, ou seja, com valores agrupados em categorias ordenadas (BOHRNSTEDT \& KNOKE, 1982). É importante salientar que, por se tratar de uma medida de associação simétrica, os valores calculados para $\gamma$ indicam tanto a capacidade de previsão da segunda variável sobre a primeira, quanto o inverso.

Em uma segunda etapa de análise nos valemos de modelos multivariados de regressão linear por mínimos quadrados (OLS) incluindo como variáveis independentes uma série de medidas relativas à indicadores sócio-demográficos e atitudinais. Com esses procedimentos esperamos testar a consistência das associações verificadas na análise bivariada inicial. Detalhes sobre esses modelos são apresentados ao longo do texto.
} 
pode ser interessante. Para tanto, a Tabela 1 apresenta os percentuais de materialistas e pós-materialistas para as quatro nações analisadas assim como de alguns países que estão em níveis distintos de desenvolvimento econômico e, sobretudo, industrial.

Tabela 1

Pós-materialismo entre países, 1991-2008

\begin{tabular}{|c|c|c|c|c|c|c|c|}
\hline \multirow[t]{2}{*}{ PAÍS } & \multirow[b]{2}{*}{ ANO } & \multicolumn{4}{|c|}{ MATERIALISMO } & \multicolumn{2}{|c|}{ PÓS-MATERIALISMO } \\
\hline & & 0 & 1 & 2 & 3 & 4 & 5 \\
\hline \multirow{4}{*}{ Argentina } & 1991 & $6,4 \%$ & $18,5 \%$ & $27,4 \%$ & $29,4 \%$ & $12,1 \%$ & $6,3 \%$ \\
\hline & 1995 & $3,6 \%$ & $14,2 \%$ & $25,9 \%$ & $28,9 \%$ & $17,8 \%$ & $9,6 \%$ \\
\hline & 1999 & $5,0 \%$ & $19,6 \%$ & $29,7 \%$ & $25,3 \%$ & $15,5 \%$ & $5,0 \%$ \\
\hline & 2006 & $8,4 \%$ & $27,3 \%$ & $31,0 \%$ & $17,2 \%$ & $11,7 \%$ & $4,4 \%$ \\
\hline \multirow{3}{*}{ Brasil } & 1991 & $7,4 \%$ & $21,3 \%$ & $31,6 \%$ & $29,2 \%$ & $8,1 \%$ & $2,4 \%$ \\
\hline & 1997 & $5,3 \%$ & $22,3 \%$ & $31,1 \%$ & $29,7 \%$ & $8,7 \%$ & $2,8 \%$ \\
\hline & 2006 & $7,7 \%$ & $24,6 \%$ & $37,5 \%$ & $17,9 \%$ & $9,7 \%$ & $2,5 \%$ \\
\hline \multirow{4}{*}{ Chile } & 1990 & $5,7 \%$ & $16,4 \%$ & $28,8 \%$ & $30,8 \%$ & $13,8 \%$ & $4,4 \%$ \\
\hline & 1996 & $4,9 \%$ & $14,9 \%$ & $31,4 \%$ & $30,5 \%$ & $14,7 \%$ & $3,7 \%$ \\
\hline & 2000 & $7,5 \%$ & $19,7 \%$ & $27,3 \%$ & $29,0 \%$ & $12,1 \%$ & $4,4 \%$ \\
\hline & 2005 & $5,3 \%$ & $19,6 \%$ & $33,7 \%$ & $23,0 \%$ & $14,6 \%$ & $3,8 \%$ \\
\hline \multirow{3}{*}{ Peru } & 1996 & $6,3 \%$ & $21,5 \%$ & $32,5 \%$ & $29,2 \%$ & $9,1 \%$ & $1,5 \%$ \\
\hline & 2001 & $4,7 \%$ & $15,1 \%$ & $31,8 \%$ & $35,2 \%$ & $10,8 \%$ & $2,3 \%$ \\
\hline & 2008 & $6,3 \%$ & $21,3 \%$ & $39,3 \%$ & $19,7 \%$ & $9,4 \%$ & $3,9 \%$ \\
\hline EUA & 2006 & $10,9 \%$ & $27,5 \%$ & $28,3 \%$ & $20,8 \%$ & $9,3 \%$ & $3,1 \%$ \\
\hline Canadá & 2006 & $2,8 \%$ & $15,1 \%$ & $28,3 \%$ & $32,6 \%$ & $15,5 \%$ & $5,6 \%$ \\
\hline França & 2006 & $5,6 \%$ & $13,8 \%$ & $27,5 \%$ & $27,1 \%$ & $18,3 \%$ & $7,6 \%$ \\
\hline Inglaterra & 2006 & $2,8 \%$ & $15,2 \%$ & $30,7 \%$ & $33,1 \%$ & $13,6 \%$ & $4,6 \%$ \\
\hline Alemanha & 2006 & $3,1 \%$ & $13,5 \%$ & $26 \%$ & $36,2 \%$ & $17,8 \%$ & $3,3 \%$ \\
\hline Itália & 2005 & $5,9 \%$ & $16,5 \%$ & $28,8 \%$ & $29,3 \%$ & $13,3 \%$ & $6,2 \%$ \\
\hline
\end{tabular}

Fonte: European and World Values Surveys four-wave Integrated data file, 1981-2004, v.20060423, 2006 e World Values Survey, 2005-2008.

Os dados corroboram a teoria do desenvolvimento humano, mostrando nos países com desenvolvimento superior os menores percentuais de materialistas. Alemanha em 2006 contava com 42,6\% de materialistas e 57,4\% de pósmaterialistas (somando os três pontos superiores da escala). Esse último grupo 
também é majoritário na França $(53,1 \%)$, Inglaterra $(51,3 \%)$ e Canadá $(53,7 \%)$, além de outros países não incluídos na tabela. Também como poderíamos antecipar, os chamados países em desenvolvimento são os que apresentam os menores percentuais de pós-materialistas, tais como o Brasil (30,1\%), Argentina $(33,3 \%)$, Chile $(41,4)$ e Peru $(33,1 \%)$. Como na base do argumento da teoria do desenvolvimento humano está o pressuposto de que a superação dos limites da segurança física e material conduz à mudança valorativa tal quadro já poderia ser antecipado.

Concentrando-nos apenas no grupo latinoamericano e levando em consideração a curta série histórica disponível, podemos identificar inclusive um retrocesso no volume de pós-materialistas aos patamares do início da década de 1990. Entre os argentinos ocorre uma ampliação considerável no percentual de pósmaterialistas "puros" entre 1991 e 1995, mas já em 1999 ocorre uma redução a níveis inferiores aos da primeira pesquisa. Em 2006 a queda continua, chegando a 4,4\%. Tomando também apenas o número de pós-materialistas "puros", verificamos no Brasil uma tendência de estagnação. A mesma situação se verifica no caso chileno. Apenas entre os peruanos ocorre movimento distinto nesse pólo extremo, ainda que a elevação seja muito tênue, partindo de 1,5\% em 1996 e atingindo 3,9\% em 2008.

Para verificar a consistência dessas tendências voltamos a dividir o índice de 12 itens em dois grupos. O Gráfico 1 apresenta a evolução dos dados para os quatro países latinoamericanos considerando apenas o somatório das frequências de indivíduos classificados entre os pontos 3 e 5 da escala. Podemos claramente identificar tendência geral de redução, com todos os países retrocedendo a níveis inferiores aos de suas respectivas primeiras medidas. Inclusive para o caso peruano. 


\section{Gráfico 1 \\ Evolução do índice de Pós-materialismo entre países latinoamericanos pós 1991-2006}

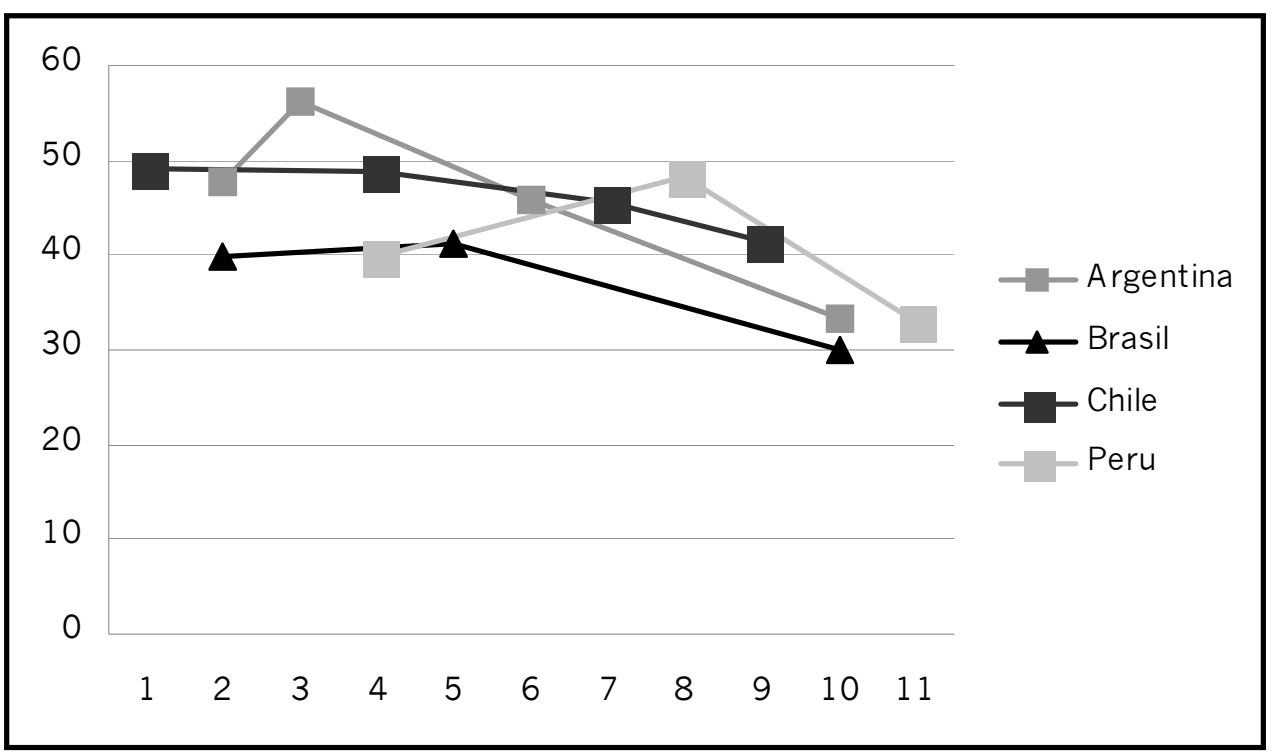

Fonte: European and World Values Surveys four-wave Integrated data file, 1981-2004 e World Values Survey, 2005-2008.

Os limites desse texto nos impedem de analisar fatores históricos e econômicos que possam explicar o movimento identificado no gráfico, mas é interessante notar a ocorrência de um relativo descompasso entre a evolução recente do PIB per capita e a síndrome de valores pós-materialistas. A melhoria nesse indicador econômico entre os países latinoamericanos não tem produzido efeitos da mesma intensidade sobre o percentual de pessoas que valorizam metas e objetivos relacionados à reorientação cultural. Defendemos que a razão desse descompasso deve ser buscada na profunda desigualdade na distribuição de renda e nos elevados níveis de pobreza que infelizmente são recorrentes na história dessa região. 


\section{Gráfico 2 \\ Produto Interno Bruto per capita em US\$ (mil), 1990-2008}

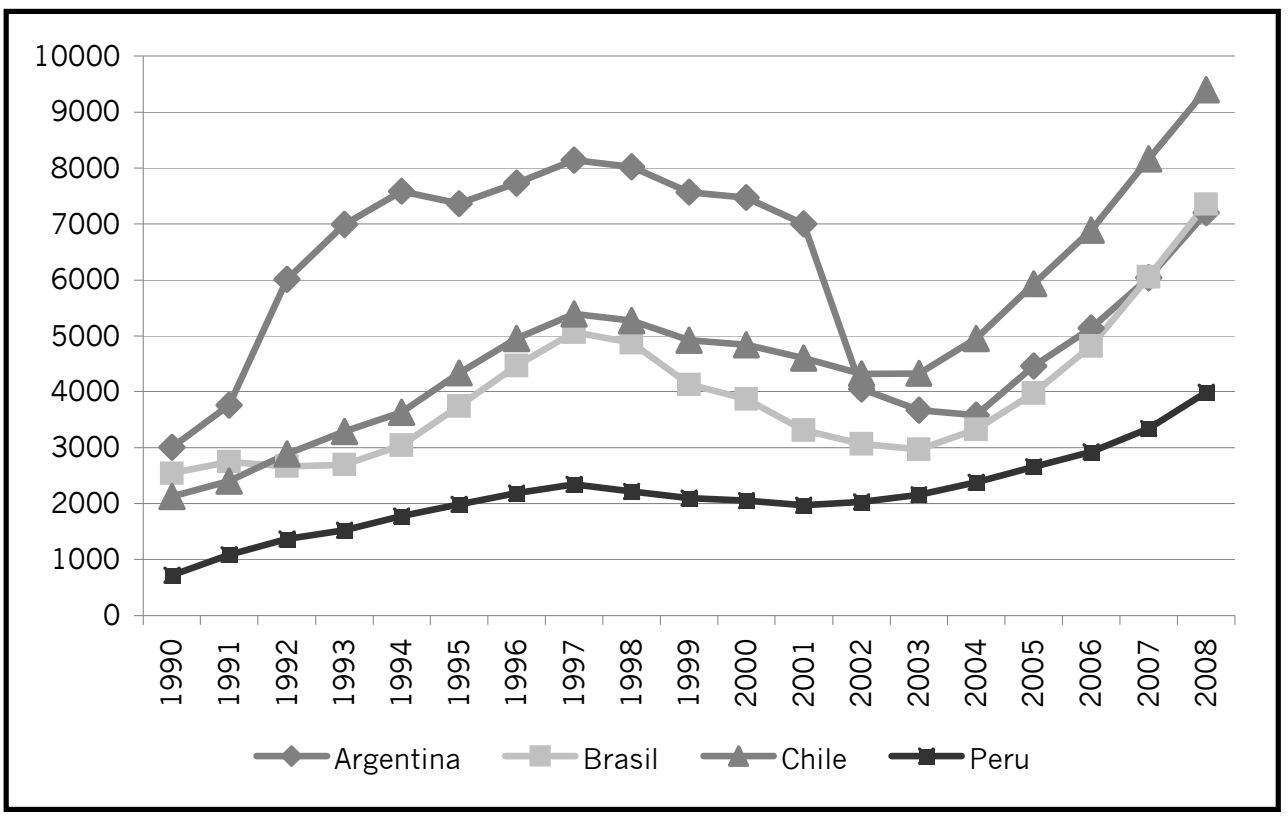

Fonte: The World Bank Group.

Notas: Produto Interno Bruto per capita convertido para dólares americanos usando o Método Atlas do Bando Mundial.

Utilizando o coeficiente de Gini $^{6}$ como medida da desigualdade na distribuição da renda verifica-se uma lamentável tendência de elevação na Argentina, Brasil e Chile; apenas o Peru registrou alguma redução. A comparação mostra que o Brasil lidera em todos os períodos de que dispomos de dados. Infelizmente, a estabilidade impressionante da desigualdade na região, mantém-se na casa dos 50 pontos por mais de três décadas de medições. Apesar dessas nações terem experimentado crescimento econômico, a estrutura de distribuição dos frutos desse desenvolvimento não possibilitou a melhoria das condições de segurança material e física necessárias à mudança das prioridades individuais da

\footnotetext{
6 Trata-se de uma medida de desigualdade proposta pelo estatístico Corrado Gini em artigo publicado na revista Variabilità e Mutabilità em 1912. É empregada para calcular a desigualdade de distribuição de renda e consiste em um número entre 0 e 1 , onde 0 corresponde à completa igualdade de renda e 1 corresponde à completa desigualdade. $\mathrm{O}$ índice de Gini é o coeficiente expresso em pontos percentuais (HOFFMANN, 1998).
} 
maioria da população, o que se reflete no baixo número de pós-materialistas verificado nas pesquisas do WVS.

\section{Tabela 2}

Índice de Gini entre países latinoamericanos, 1960-1995

\begin{tabular}{|c|c|c|c|c|c|c|c|c|c|c|c|c|}
\hline \multirow{2}{*}{ PAÍS } & \multicolumn{12}{|c|}{ Coeficiente de GINI } \\
\hline & 1960 & 1961 & 1969 & 1970 & 1971 & 1979 & 1980 & 1981 & 1989 & 1990 & 1991 & 1995 \\
\hline Argentina & . & 41,9 & . & 39,40 & . & . & 41,6 & 42,0 & . & 44,4 & 45,2 & 47,4 \\
\hline Brasil & 53,0 & . & . & 57,61 & . & 59,44 & 57,78 & 55,42 & 59,60 & 60,5 & . & 59,2 \\
\hline Chile & . & . & . & . & 50,09 & 51,79 & 52,57 & 52,15 & 51,88 & 53,18 & 55,38 & 54,5 \\
\hline Peru & . & . & . & . & 55,0 & . & . & 49,83 & . & 43,81 & 43,7 & . \\
\hline
\end{tabular}

Fonte: World Income Inequality Database/World Institute for Development Economic Research. Nota: Em razão da falta de dados não foi possível seguir intervalos regulares de tempo.

Não basta, portanto, que ocorra desenvolvimento econômico para que a síndrome de valores pós-materialistas, com todos os seus efeitos sociais e políticos, se desenvolva em uma nação. A distribuição dos benefícios oriundos desse crescimento da maneira mais igualitária possível é condição fundamental para que tal processo se concretize. A continuidade de altos níveis de desigualdade pode limitar em muito os efeitos de períodos de relativa prosperidade sobre a adesão a metas e objetivos não ligados às preocupações materiais.

A posição dos países selecionados para esse estudo no quadro geral da mudança cultural, todavia, não inviabiliza os testes que propomos. Não pretendemos aqui testar se o contingente de pós-materialistas nessas nações impacta os indicadores de participação política, pois nosso objetivo se localiza no plano das individualidades, ou seja, nos interessa verificar se a adesão a esses valores peculiares altera no plano individual as disposições e atitudes participativas nos cidadãos desses quatro países.

O fato de Argentina, Brasil, Chile e Peru terem experimentado processos de modernização e industrialização tardias associados à persistência das desigualdades internas pode explicar de maneira plausível o baixo percentual de pós-materialistas e até mesmo a não ocorrência de vários fenômenos associados; entretanto, não nos autoriza a deduzir que materialistas e pós-materialistas possuem as mesmas orientações e atitudes em relação aos mecanismos de envolvimento político, sejam eles tradicionais ou não convencionais. É justamente isso que pretendemos verificar. 


\section{Os contextos nacionais}

Como se sabe, o Chile é o país latinoamericano com os melhores indicadores econômicos e sociais. Tem sido apresentado como o único da região que poderia ser incluído no rol dos "desenvolvidos". Porém, sob o aspecto da cultura política, o caso chileno levanta várias questões sobre o impacto que a longa e violenta ditadura militar teve no sistema de crenças políticas da população. Alguns autores (KRISCHKE, 2003) o apontam como um dos países de maior tradição democrática da América Latina, antes do golpe de 1973. O país também foi o primeiro que implementou as reformas liberais e cujos reflexos podem ser sentidos tanto no plano econômico como político. A longa ditadura provocou a erosão das bases da sociabilidade democrática, como também eliminou as identidades partidárias, fortemente constituídas antes do golpe de Pinochet. Por fim, o neoliberalismo, que conta com apoio significativo dos chilenos, como demonstram outras pesquisas (CASTRO, 2000, VALDIVIESO, 2008), serve também como substrato ideológico despolitizador e desmobilizador. Tais variáveis se refletem no comportamento dos chilenos, com níveis relativamente baixos de satisfação com a democracia ${ }^{7}$, e tendo seu comportamento político fortemente orientado pelo personalismo (BORBA, 2007).

O Peru apresenta um quadro semelhante ao do Chile. O relativo crescimento econômico verificado nos últimos anos não tem se refletido nos índices de apoio à democracia, na satisfação com o regime, nem na identificação dos cidadãos com as instituições democráticas. Carrón e Zarate (2008, p. 9) chegam a afirmar que "el Perú ocupa lugares bastante bajos en la región en una serie de actitudes relacionadas con el apoyo a una democracia estable". Em termos de satisfação com a democracia, o país somente está acima do Haiti e do Paraguai (2008, LAPOP), com $42,7 \%$. As razões de tal paradoxo entre um desempenho econômico positivo e valores políticos pautados por julgamentos essencialmente negativos para com as instituições democráticas tem sido explicado por várias razões, entre elas, o peso da tradição autoritária, que teve sua recente manifestação no período de Fujimori (1990-2000), o papel despolitizador das reformas orientadas para o mercado implementadas por este governo; os altíssimos níveis de corrupção e a grande insegurança social (CARRIÓN \& ZÁRATE, 2008).

A Argentina apresenta um paradoxo inverso aos dois países descritos acima. Apesar do país ter mergulhado em uma profunda crise econômica a partir do final da década de 1990, as taxas de apoio à democracia, segundo a dimensão churchiliana são significativamente mais altas que seus vizinhos latinoamericanos,

\footnotetext{
${ }^{7}$ Segundo o Latin American Public Opinion Project, em 2008, 48,1\% dos chilenos se dizem satisfeitos com a democracia em 2008; um dos índices mais baixos da região),
} 
acima inclusive das avaliações feitas pelos norte-americanos ${ }^{8}$. A Argentina também passou por reformas econômicas neoliberais, porém a crise veio acompanhada de um aumento explosivo da mobilização social e da crítica às instituições representativas tradicionais. Tais movimentos tiveram uma forte base popular como demonstra Vitullo (2007) ao estudar o "movimento dos piqueteiros" e as mobilizações políticas em torno dos votos em branco e nulos. O país parece ter presenciado a expressão de uma "cidadania crítica", nos moldes destacados por Inglehart e seus colaboradores, em que a crítica às instituições representativas não se reflete em atitudes anti-democráticas; pelo contrário, se materializa na valorização de novas instituições, menos hierárquicas e mais próximas do contato direto com os cidadãos. O país, porém, apresenta um dos índices mais altos da região, em termos de vitimização pela corrupção (27,5\%), abaixo apenas de Haiti, Bolívia e México, e está no topo da vitimização por delito (ou seja, pessoas que afirmaram ter sido vitimas de algum crime), com $27,5 \%$ da população.

O Brasil é o país que atualmente apresenta o maior PIB da região, tendo experimentado relativa estabilidade econômica nos últimos 10 anos; porém apresenta índices elevadíssimos em termos das desigualdades sociais. No plano da cultura política, ocupa uma posição intermediária em termos de apoio a democracia, com 70,5\% da população apoiando o regime (LAPOP, 2008), logo acima do Chile. Apresenta também índices moderados de satisfação com a democracia (53\%). Está próximo ao Chile em termos de vitimização pela corrupção (11,5\% contra $48,2 \%$ do país mais alto na escala, o Haiti) e apresenta também índices intermediários de vitimização por delitos (16,3\%). O Brasil apresenta, porém, um dos mais baixos índices de legitimidade das instituições democráticas $(36,6 \%)$, bem abaixo do Chile $(46,2 \%)$ e próximo de Argentina e Peru (36,2\% e $34,4 \%$, respectivamente).

\section{Valores pós-materialistas e interesse por política}

O nível de interesse dos cidadãos por política tem sido empregado com relativa freqüência nos estudos sobre cultura política como indicador de uma postura participativa (ALMOND \& VERBA, 1989; INGLEHART, 2001). Em perspectiva mundial, dados coletados pelo WVS entre os anos de 1981 e 1990 indicaram uma tendência de elevação no número de entrevistados que se diziam interessados em alguma medida. Assim, verificada redução na participação por meio do voto e pelo engajamento em partidos (NORRIS, 1999), portanto, não estaria sendo acompanha da apatia política dos cidadãos (INGLEHART, 2001).

\footnotetext{
8 86,9\% na Argentina, 78,4\% nos Estados Unidos, 69,5\% no Chile, 65,5\% no Peru.
} 
Como mostra a Tabela 3, os dados de 2006 relativos aos quatro países incluídos em nossa pesquisa revelam que o nível de interesse é pequeno, não chegando em nenhum dos casos a $50 \%$ de interessados quando somamos aqueles que manifestaram "muito interesse" e "algum interesse". O Brasil foi o que alcançou melhor posição, com $48,6 \%$ de interessados, e os peruanos manifestaram o menor interesse $(21,8 \%)$.

Tabela 3

Interesse em política por país, 2006

\begin{tabular}{|l|c|c|c|c|}
\hline \multirow{2}{*}{ PAÍS } & \multicolumn{4}{|c|}{ INTERESSE (\%) } \\
\cline { 2 - 5 } & Muito interesse & Algum interesse & Pouco interesse & Nenhum interesse \\
\hline Argentina & 5,0 & 19,2 & 32,8 & 43,0 \\
\hline Brasil & 11,8 & 36,8 & 26,4 & 25,0 \\
\hline Chile & 5,8 & 18,1 & 27,8 & 48,2 \\
\hline Peru & 6,3 & 15,5 & 39,6 & 38,5 \\
\hline
\end{tabular}

Fonte: WORLD VALUES SURVEY OFFICIAL DATA FILE v.20081015, 2008. World Values Survey Association.

A partir dos dados das diversas pesquisas realizadas pelo WVS nesses países podemos identificar que, contrariamente ao verificado em perspectiva mundial na década de 90 por Inglehart (2001), a tendência de ampliação no nível de interesse não se manteve constante. Na Argentina, em 1991 o percentual de entrevistados que disseram ter "muito interesse" ou "algum interesse" era de $30,2 \%$, caiu para 25,3\% em 1995, para 18,3\% em 1999 e apenas na pesquisa de 2006 mostrou recuperação, chegando a 24,2\%. No Brasil o percentual em 1991 era de 47,4 pontos, em 1997 caiu consideravelmente para 31,1\% e em 2006 mostrou recuperação impressionante chegando a 48,6\%. No Chile, em de 1990 o percentual de interessados era de 36,7\%, em 1996 foi reduzido para 20,3\%, subiu para $24,9 \%$ em 2000 e voltou a cair 1 ponto percentual em 2006. Entre os peruanos 32,9\% se mostraram interessados em 1996, em 2001 esse percentual se elevou significativamente para 47,6 pontos e voltou a cair em 2006 , chegando a $21,8 \%$.

A inexistência de uma tendência única na região e a variação em curtos períodos de tempo obviamente demandam análises qualitativas sobre os acontecimentos e fenômenos políticos nacionais, tarefas que ultrapassam os objetivos imediatos desse texto.

O cruzamento da variável de interesse por política com o índice de materialismo/pós-materialismo foi favorável à hipótese da associação, como constata-se na Tabela 4. Em todos os países os coeficientes foram estatisticamente significativos e positivos, indicando que elevações no índice que 
mede as prioridades valorativas são acompanhadas por manifestações de maior interesse por política. A mais forte associação foi verificada na Argentina (,21) e a menor no Brasil (,09).

Tabela 4

Pós-materialismo e interesse por política por país, 2006

\begin{tabular}{|l|l|c|c|c|c|c|c|}
\hline \multirow{2}{*}{ PAÍS } & \multicolumn{5}{|c|}{ ÍNDICE DE MATERIALISMO/PÓS-MATERIALISMO } \\
\cline { 3 - 8 } & Materialista & 1 & 2 & 3 & 4 & Pós-materialista \\
\hline \multirow{3}{*}{$\begin{array}{l}\text { Argentina } \\
y=, 21 \\
p=, 000\end{array}$} & Nenhum interesse & 12,6 & 30,4 & 31,6 & 11,5 & 9,1 & 4,7 \\
\cline { 2 - 8 } & Pouco interesse & 5,8 & 25,8 & 33,5 & 18,5 & 12,6 & 3,7 \\
\cline { 2 - 8 } & Algum interesse & 4,2 & 23,7 & 27,9 & 25,3 & 14,7 & 4,2 \\
\cline { 2 - 8 } & Muito interesse & 4,0 & 20,0 & 26,0 & 26,0 & 16,0 & 8,0 \\
\hline \multirow{3}{*}{$\begin{array}{l}\text { Brasil } \\
y=, 09 \\
p=, 004\end{array}$} & Nenhum interesse & 7,3 & 28,3 & 37,0 & 17,9 & 8,2 & 1,4 \\
\cline { 2 - 8 } & Pouco interesse & 9,5 & 23,9 & 41,1 & 15,9 & 7,5 & 2,1 \\
\cline { 2 - 8 } & Algum interesse & 7,4 & 21,7 & 37,6 & 19,2 & 11,8 & 2,4 \\
\cline { 2 - 8 } & Muito interesse & 6,3 & 27,6 & 28,7 & 19,0 & 11,5 & 6,9 \\
\hline \multirow{3}{*}{$\begin{array}{l}\text { Chile } \\
y=, 16 \\
p=, 000\end{array}$} & Nenhum interesse & 5,2 & 22,4 & 38,5 & 20,1 & 11,7 & 2,1 \\
\cline { 2 - 8 } & Pouco interesse & 6,5 & 17,0 & 29,7 & 26,4 & 18,1 & 2,2 \\
\cline { 2 - 8 } & Algum interesse & 3,3 & 18,9 & 26,7 & 26,7 & 17,2 & 7,2 \\
\cline { 2 - 8 } & Muito interesse & 6,9 & 12,1 & 34,5 & 17,2 & 13,8 & 15,5 \\
\hline \multirow{3}{*}{$\begin{array}{l}\text { Peru } \\
y=, 12 \\
p=, 000\end{array}$} & Nenhum interesse & 7,5 & 23,1 & 39,3 & 19,7 & 7,7 & 2,8 \\
\cline { 2 - 8 } & Pouco interesse & 5,8 & 22,5 & 40,6 & 19,3 & 8,8 & 3,0 \\
\cline { 2 - 7 } & Algum interesse & 4,3 & 15,9 & 36,6 & 21,1 & 13,4 & 8,6 \\
\cline { 2 - 7 } & Muito interesse & 6,4 & 16,0 & 39,4 & 18,1 & 14,9 & 5,3 \\
\hline
\end{tabular}

Fonte: WORLD VALUES SURVEY OFFICIAL DATA FILE v.20081015, 2008. World Values Survey Association.

Para identificar a consistência da associação entre pós-materialismo e essa primeira variável sobre atitudes participativas realizamos também análises de regressão tomando como medida dependente a escala na qual os indivíduos classificam seu nível de interesse por política e, como variáveis independentes, o índice de 12 itens e medidas socioeconômicas que favorecem a identificação dos entrevistados segundo a sua posição na estrutura social. A inclusão dessas variáveis é diretamente inspirada por vasta literatura que defende a existência de associação entre uma posição de centralidade social e a maior propensão à participação. As 
origens de tal reflexão podem ser encontradas na obra de Milbrath e Goel (1965) ao apontar, a partir de pesquisas empíricas realizadas nos Estados Unidos, que os níveis mais elevados de participação podem ser encontrados naqueles com maior escolaridade, os provenientes das classes médias, os homens em relação às mulheres, aqueles com idade intermediária, os casados, os que moram nas cidades em relação aos que moram no campo, os que moram há muito tempo num lugar em relação aos que acabam de se transferir, as maiorias étnicas, e aqueles engajados socialmente. Da mesma forma, Verba e Nie (1972), Verba e Schlozman e Brady (1995) identificaram através de pesquisas comparadas em vários países uma correspondência entre status social e participação. Tal modelo foi conceituado como da "centralidade", pois identifica que "a intensidade da participação varia conforme a posição social do indivíduo pois, quanto mais central do ponto de vista da estrutura social, maior a participação; quanto mais central a respeito de um grupo social, maior o senso de agregação" (AVELAR, 2004, p. 229). O modelo da centralidade tem sua base explicativa na ideia de que "Usually, higher social status implies more material resources (but also free time) to invest in political participation, but also a higher probability of being successful (via personal relationships with powerful individuals) and especially a higher sense of personal achievement." (DELLAPORTA, 2008, p.9) ${ }^{9}$.

\footnotetext{
9 De acordo com Reis (2000), a teoria da centralidade propõe uma relação de causalidade entre posição social do indivíduo - medida de forma tanto objetiva (posição socioeconômica) quanto subjetiva ("aspectos socioposicológicos e intelectuais tais como o grau de informação sobre questões políticas..." (p.261) - e os níveis de participação. A "centralidade" objetiva teria uma dimensão vertical ("posição de classe e status socioeconômico" p.298) e outra horizontal ("experiência urbana" idem). A tese que perpassa a teoria é de que "quanto mais alta a posição de classe e quanto maior a integração na vida das cidades, com sua contra partida de alargamento do horizonte intelectual-psicológico e de maior exposição a informações de todo tipo, tanto maior a participação política" (REIS, 2000, p. 298).
} 
Tabela 5

Preditores do interesse por política, 2006

\begin{tabular}{|c|c|c|c|c|}
\hline País & & $\mathrm{B}$ & Beta & $P$ \\
\hline \multicolumn{5}{|c|}{ Argentina $^{1}$} \\
\hline & Índice de materialismo/pós-materialismo &, 074 &, 106 & ,064 \\
\hline & Escolaridade &, 176 & ,272 & ,001 \\
\hline & Sexo &, 236 &, 132 & ,000 \\
\hline & Classe social (subjetiva) & ,081 & ,075 &, 000 \\
\hline & Idade &, 027 & ,091 & ,025 \\
\hline \multicolumn{5}{|c|}{ Brasil } \\
\hline & Índice de materialismo/pós-materialismo &, 026 &, 031 &, 251 \\
\hline & Escolaridade &, 104 &, 181 & ,000 \\
\hline & Sexo &, 083 &, 042 &, 107 \\
\hline & Classe social (subjetiva) &,- 005 &,- 004 & ,887 \\
\hline & Renda &,- 003 &,- 006 & ,839 \\
\hline & Idade &, 008 &, 022 & ,407 \\
\hline \multicolumn{5}{|l|}{ Chile } \\
\hline & Índice de materialismo/pós-materialismo & ,086 &, 110 & ,001 \\
\hline & Escolaridade &, 083 &, 131 &, 002 \\
\hline & Sexo &, 225 &, 120 &, 000 \\
\hline & Classe social (subjetiva) &, 148 &, 146 &, 000 \\
\hline & Renda &, 003 &, 006 &, 890 \\
\hline & Idade & ,010 & ,030 & ,397 \\
\hline \multicolumn{5}{|l|}{ Peru } \\
\hline & Índice de materialismo/pós-materialismo & ,054 & ,070 &, 013 \\
\hline & Escolaridade &, 094 &, 161 &, 000 \\
\hline & Sexo &, 174 & ,098 &, 000 \\
\hline & Classe social (subjetiva) &, 048 &, 047 &, 112 \\
\hline & Renda & ,009 & ,018 &, 593 \\
\hline & Idade & ,008 & ,022 & ,426 \\
\hline
\end{tabular}

Notas: 1) Não existem dados sobre renda para a Argentina, desta forma seu modelo envolve apenas cinco variáveis;

2) $R^{2}$ Ajustado: Argentina= ,121; Brasil=,034; Chile=,088; Peru=,053;

3) Método Enter.

Fonte: WORLD VALUES SURVEY OFFICIAL DATA FILE v.20081015, 2008. World Values Survey Association. 
Os resultados dispostos na Tabela 5 são bastante interessantes e revelam certa fragilidade da tese da associação defendida pelos autores vinculados à teoria do desenvolvimento humano. No caso da Argentina. constatamos que o índice de materialismos/pós-materialismo deixa de produzir efeito significativo, perdendo espaço principalmente para o nível de escolaridade ${ }^{10}$, mas também para o sexo dos entrevistados. Entre a população argentina mais relevante do que possuir valores pós-materialistas seria, primeiramente, possuir escolaridade elevada e, na seqüência, ser homem. Entre os brasileiros algo semelhando ocorre, entretanto, sem a presença de efeito significativo na variável sexo. A única medida capaz de influenciar o nível de interesse por política dos brasileiros no contexto do modelo proposto foi a escolaridade. No caso do Chile. o índice apresenta efeito significativo, entretanto, é preciso salientar que ocupa apenas a quarta posição em termos comparativos, ficando atrás da escolaridade, da classe social subjetiva e sexo. Entre os peruanos, dentre as três variáveis que produziram efeito significativo o mencionado índice ocupa a última posição, merecendo destaque a expressiva distância que separa o seu efeito daquele produzido pela escolaridade.

Ainda que em dois dos quatro países a associação positiva continue sendo encontrada, a comparação com outras medidas relevantes indica que a capacidade explicativa da mudança pós-materialista sobre essa primeira variável de participação é frágil.

Para finalizar, é interessante notar que no modelo a variável idade, que pensamos ser algo relevante na explicação do interesse por política ${ }^{11}$, em três dos quatro países não se mostrou importante, não alcançando sequer o nível mínimo de significância estatística. Apenas entre os brasileiros essa exigência foi satisfeita, porém com um dos menores efeitos na comparação com as demais variáveis preditoras. Ao que tudo indica, não existem diferenciais no nível de interesse por política em termos geracionais no contexto dos países analisados.

\footnotetext{
10 Preocupados com a existência de possível colinearidade entre escolaridade e o índice de materialismo/pós-materialismo realizamos os testes de Tolerância e o de Variance Inflation Factor (VIF) para os quais encontramos valores dentro do que a literatura define como aceitáveis, ou seja, maiores que 0,10 na Tolerância e maiores que 5 no VIF em ambas as variáveis e para os quatro países (O'BRIEN, 2007).

11 A relevância da variável idade no contexto dos países analisados se deve principalmente ao fato de que, em razão dos processos recentes de democratização, as novas gerações terem sido submetidas a experiências políticas significativamente distintas daquelas vivenciadas por grupos geracionais mais velhos. Considerando que tais experiências que se dão na vida pré-adulta e adulta produzem impacto sobre os valores políticos dos indivíduos, seria plausível supor que indivíduos que viveram parte importante de sua vida sob a vigência de instituições democráticas possuíssem orientações e atitudes potencialmente mais congruentes com uma postura participativa e interessada. Testes preliminares dessa e de outras hipóteses relacionadas podem ser encontradas em Ribeiro (2007).
} 


\section{Pós-materialismo e participação}

Partimos agora para variáveis mais diretamente ligadas ao nível da ação. Isso é possível porque o WVS disponibiliza um conjunto de dados relativos à atuação voluntária dos entrevistados em diferentes instituições, organizações ou atividades. Essas informações são geradas através de questões que levam os indivíduos a escolherem, em relação a um leque de organizações ou atividades voluntárias, a alternativa que melhor define sua situação: não participa, é membro inativo ou é membro ativo.

As tabelas que seguem apresentam os cruzamentos entre algumas dessas variáveis e o índice de materialismo/pós-materialismo. Dentre as organizações envolvidas nas perguntas, selecionamos aquelas que desempenham papel político mais relevante nos regimes democráticos contemporâneos.

Antes de apresentar os dados sobre as associações, seria interessante analisar em cada caso os níveis atuais de atividade dos públicos das quatro nações e também como tem sido sua evolução ao longo do período histórico coberto pelo WVS.

A Tabela 6 , com dados referentes à pesquisa de 2006, mostra um quadro de baixa participação. No que diz respeito aos sindicatos, o Brasil é o país que conta com maior percentual de participação ativa, com mais que o dobro de pontos em relação aos segundos colocados, Chile e Peru (empatados com 4,3\%). Se somarmos os percentuais de membros ativos e inativos, o Brasil $(18,9)$ continua na liderança, mas a última posição passa a ser ocupada pelo Peru $(6,3)$.

Consulta às séries históricas revela considerável estabilidade nesses números, como no caso da Argentina que registrou 1,5\% de participantes ativos em 1984, 1,8\% em 1995 e 1,4 em 2006. O Brasil, que em 1997 aparece com 9,7\% de membros ativos, expressa pequena queda para $8,7 \%$ em 2006. Chile, que contava em 1996 com 5,4\% também registrou pequena queda para 4,3\%. Por fim, em 1996 $4,2 \%$ dos peruanos declararam participar ativamente de sindicatos, contra $4,3 \%$ em 2006.

A participação em partidos políticos é igualmente pequena segundo a última pesquisa do WVS, sendo o maior percentual de membros ativos também registrado no Brasil, com 5,3\%. No caso brasileiro, inclusive se verifica uma redução na comparação com os dados de 1997, quando 7,2\% dos entrevistados se definiram como membros ativos dessas instituições políticas. De forma distinta, entre os peruanos esse percentual passa de $2,6 \%$ para $4,8 \%$ em 2006. No Chile a variação foi muito pequena, passando de 2,8\% em 1996 para $2 \%$ dez anos depois. O Peru que em 1996 contava com 2,6\% de membros ativos teve o maior aumento, 
passando a $4,8 \%$ na última pesquisa. Entre avanços e retrações o que chama mais a atenção é uma manifesta falta de atuação partidária desses públicos.

Tabela 6

Participação em organizações/atividades voluntárias por país, 2006 (\%)

\begin{tabular}{|l|c|c|c|}
\hline & \multicolumn{3}{|c|}{ SINDICATOS } \\
\hline & $\begin{array}{c}\text { Não } \\
\text { Participa }\end{array}$ & $\begin{array}{c}\text { Participa como membro } \\
\text { inativo }\end{array}$ & $\begin{array}{c}\text { Participa } \\
\text { ativamente }\end{array}$ \\
\hline Argentina & 90,2 & 8,4 & 1,4 \\
\hline Brasil & 81,1 & 10,2 & 8,7 \\
\hline Chile & 83,0 & 12,7 & 4,3 \\
\hline Peru & 93,6 & 2,0 & 4,3 \\
\hline & \multicolumn{3}{|c|}{ PARTIDOS POLITICOS } \\
\hline Argentina & 89,2 & 8,4 & 2,4 \\
\hline Brasil & 89,8 & 5,0 & 5,3 \\
\hline Chile & 86,1 & 11,9 & 2,0 \\
\hline Peru & 92,7 & 2,5 & 4,8 \\
\hline & \multicolumn{3}{|c|}{ ORGANIZAÇÕES AMBIENTAIS } \\
\hline Argentina & 89,6 & 8,8 & 1,6 \\
\hline Brasil & 93,0 & 3,4 & 3,6 \\
\hline Chile & 87,1 & 11,3 & 5,3 \\
\hline Peru & 93,1 & 1,5 & 3,3 \\
\hline & \multicolumn{3}{|c|}{ ASSOCIAÇÕES PROFISSIONAIS } \\
\hline Argentina & 89,1 & 7,6 & 3,7 \\
\hline Brasil & 85,8 & 5,5 & 6,5 \\
\hline Chile & 84,9 & 11,2 & \\
\hline Peru & 91,9 & 1,6 & \\
\hline
\end{tabular}

Fonte: WORLD VALUES SURVEY OFFICIAL DATA FILE v.20081015, 2008. World Values Survey Association.

Os baixos níveis se repetem em relação à participação em organizações ligadas a questões ambientais, com uma inversão de posições entre Peru e Brasil, com o primeiro ocupando a primeira posição. A Argentina, que em 1984 contava com apenas 0,4\% de participação ativa nesse tipo de organização, passou para 2,6\% em 1995 e voltou a cair em 2006, com 1,6\%. Os brasileiros, que em 1997 contavam com $6,2 \%$ também expressaram redução para $3,6 \%$. Chile, que na pesquisa de 1996 contava com 3,8\%, em 2006 também reduziu esse nível de atuação para 1,6\%. Por fim, Peru que em 1996 tinha 3\% de membros ativos passou a contar com 5,3\% em 2006.

No que se refere à participação em associações profissionais os números também não são muito expressivos e o Brasil novamente apresenta os maiores percentuais, seguido pelo Peru. Aqui constatamos uma tendência geral de queda, 
com todos os países registrando em 2006 percentuais inferiores aos verificados nas pesquisas conduzidas entre 1995 e 1997.

No que se refere ao tema da relação entre participação nessas organizações/atividades e a adesão aos valores pós-materialistas, as tabelas a seguir fornecem indicações interessantes.

A Tabela 7 revela que participação em sindicatos não está associada com a escala de materialismo/pós-materialismo, pois em nenhum dos países os níveis de significância se mostraram maiores do que o mínimo necessário $(p=0,05)$.

Tabela 7

Participação em sindicatos e Pós-materialismo por país, 2006 (\%)

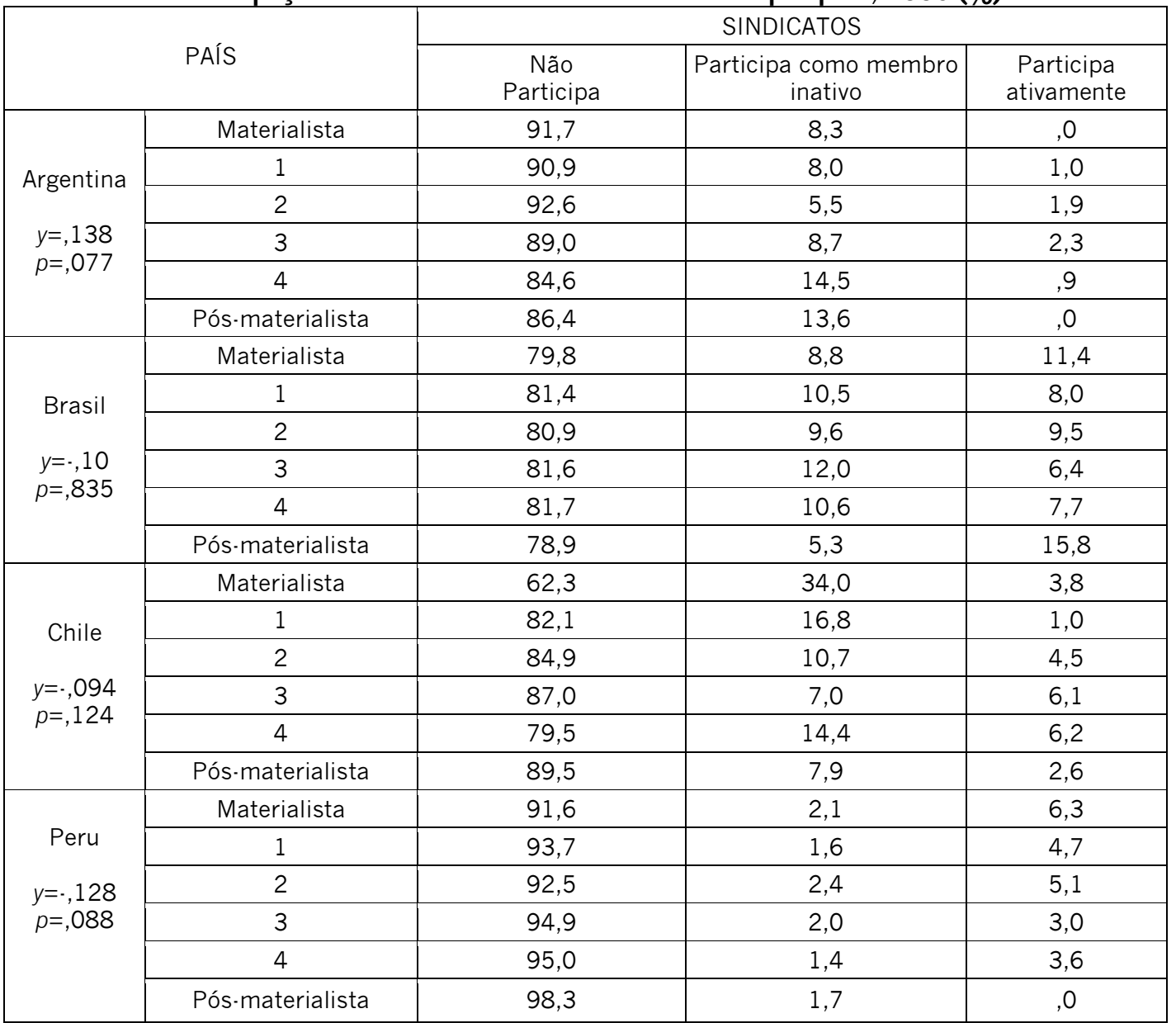

Fonte: WORLD VALUES SURVEY OFFICIAL DATA FILE v.20081015, 2008. World Values Survey Association. 
Como aparece na Tabela 8, a mesma situação ocorre em relação ao cruzamento envolvendo a atuação em partidos políticos. Aqui também os valores de p são superiores ao mínimo exigido, revelando que materialistas e pós-materialistas não se distinguem em relação a esse tipo de participação política.

Tabela 8

Participação em partidos políticos e pós-materialismo por país, 2006 (\%)

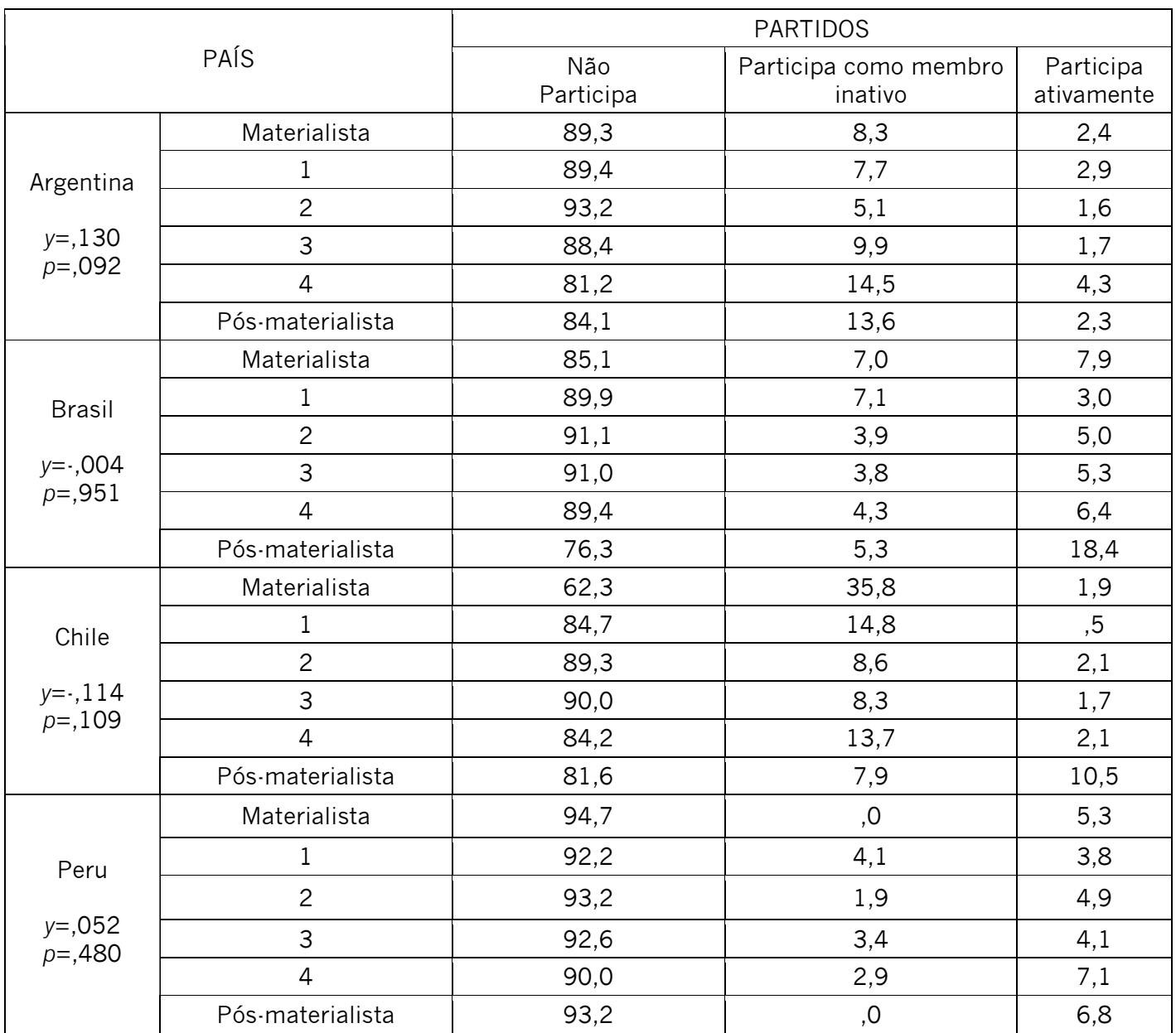

Fonte: WORLD VALUES SURVEY OFFICIAL DATA FILE v.20081015, 2008. World Values Survey Association

A situação se altera quando realizamos testes envolvendo a participação em organizações/atividades relacionadas a questões ambientais, como mostra a Tabela 9. Na Argentina encontramos um $y=0,20(p=0,012)$, indicando que a adesão aos chamados valores pós-materialistas está associada à atuação nesse tipo de 
atividade. Tais resultados são compatíveis com as hipóteses da teoria do desenvolvimento humano, que relacionam 0 abandono de preocupações materialistas com crescimento econômico à atribuição de maior importância a questões relacionadas à preservação ambiental. A confirmação, entretanto, não abrange o caso chileno, pois o coeficiente negativo $(y=-0,15)$ mostra que elevações no índice de pós-materialismo produzem o efeito contrário.

Tabela 9

Participação em organizações ambientais e Pós-materialismo por país, 2006 (\%)

\begin{tabular}{|c|c|c|c|c|}
\hline \multirow[b]{2}{*}{ PAÍS } & & \multicolumn{3}{|c|}{ ORGANIZAÇÕES AMBIENTAIS } \\
\hline & & $\begin{array}{c}\text { Não } \\
\text { Participa }\end{array}$ & $\begin{array}{l}\text { Participa como } \\
\text { membro inativo }\end{array}$ & $\begin{array}{l}\text { Participa } \\
\text { ativamente }\end{array}$ \\
\hline \multirow{6}{*}{$\begin{array}{c}\text { Argentina } \\
y=, 199 \\
p=, 012\end{array}$} & Materialista & 90,5 & 8,3 & 1,2 \\
\hline & 1 & 90,5 & 8,4 & 1,1 \\
\hline & 2 & 93,9 & 4,8 & 1,3 \\
\hline & 3 & 89,5 & 9,3 & 1,2 \\
\hline & 4 & 77,8 & 17,1 & 5,1 \\
\hline & Pós-materialista & 84,1 & 15,9 & , 0 \\
\hline \multirow{6}{*}{$\begin{array}{l}\text { Brasil } \\
y=, 090 \\
p=, 259\end{array}$} & Materialista & 91,1 & 3,6 & 5,4 \\
\hline & 1 & 93,4 & 3,8 & 2,7 \\
\hline & 2 & 94,5 & 2,5 & 3,0 \\
\hline & 3 & 94,7 & 1,9 & 3,4 \\
\hline & 4 & 85,9 & 7,0 & 7,0 \\
\hline & Pós-materialista & 86,8 & 10,5 & 2,6 \\
\hline \multirow{6}{*}{$\begin{array}{c}\text { Chile } \\
\begin{array}{c}y=-, 147 \\
p=, 045\end{array}\end{array}$} & Materialista & 67,9 & 30,2 & 1,9 \\
\hline & 1 & 83,7 & 14,8 & 1,5 \\
\hline & 2 & 90,5 & 8,3 & 1,2 \\
\hline & 3 & 90,4 & 7,8 & 1,7 \\
\hline & 4 & 85,6 & 13,7 &, 7 \\
\hline & Pós-materialista & 86,8 & 5,3 & 7,9 \\
\hline \multirow{6}{*}{$\begin{array}{l}\text { Peru } \\
y=, 116 \\
p=, 110\end{array}$} & Materialista & 97,9 & 1,1 & 1,1 \\
\hline & 1 & 93,7 & 1,6 & 4,7 \\
\hline & 2 & 92,7 & 1,5 & 5,8 \\
\hline & 3 & 92,2 & 2,0 & 5,7 \\
\hline & 4 & 93,6 & ,7 & 5,7 \\
\hline & Pós-materialista & 89,7 & 1,7 & 8,6 \\
\hline
\end{tabular}

Fonte: WORLD VALUES SURVEY OFFICIAL DATA FILE v.20081015, 2008. World Values Survey Association. 
Os testes envolvendo a participação em associações profissionais (Tabela 10) também apontam interessantes contradições. Como os dados revelam, na Argentina $(y=0,25)$ e no Peru $(y=27)$ existem associações com coeficientes moderados. Ou seja, entre os públicos desses dois países existe uma considerável relação entre aderir a metas e objetivos pós-materialistas e participar de associações dessa natureza. No caso brasileiro, a associação não se mostrou estatisticamente significativa e, como no caso anterior, no Chile o coeficiente foi negativo $(y=-0,16)$.

Tabela 10

Participação em associações profissionais e Pós-materialismo por país, 2006 (\%)

\begin{tabular}{|c|c|c|c|c|}
\hline & \multirow[b]{2}{*}{ PAÍS } & \multicolumn{3}{|c|}{ ORGANIZAÇÕES PROFISSIONAIS } \\
\hline & & \multirow{2}{*}{$\begin{array}{c}\text { Não } \\
\text { Participa } \\
91,7 \\
\end{array}$} & \multirow{2}{*}{$\begin{array}{l}\text { Participa como } \\
\text { membro inativo } \\
7,1 \\
\end{array}$} & \multirow{2}{*}{$\begin{array}{c}\begin{array}{c}\text { Participa } \\
\text { Ativamente }\end{array} \\
1,2\end{array}$} \\
\hline \multirow{6}{*}{$\begin{array}{l}\text { Argentina } \\
\begin{array}{l}y=, 246 \\
p=, 001\end{array}\end{array}$} & Materialista & & & \\
\hline & 1 & 92,0 & 6,6 & 1,5 \\
\hline & 2 & 91,6 & 5,5 & 2,9 \\
\hline & 3 & 86,0 & 8,7 & 5,2 \\
\hline & 4 & 81,2 & 12,8 & 6,0 \\
\hline & Pós-materialista & 81,8 & 11,4 & 6,8 \\
\hline \multirow{6}{*}{$\begin{array}{l}\text { Brasil } \\
y=, 091 \\
p=, 095\end{array}$} & Materialista & 84,7 & 8,1 & 7,2 \\
\hline & 1 & 87,6 & 5,2 & 7,2 \\
\hline & 2 & 86,8 & 5,0 & 8,2 \\
\hline & 3 & 85,3 & 4,5 & 10,2 \\
\hline & 4 & 81,7 & 7,7 & 10,6 \\
\hline & Pós-materialista & 75,0 & 5,6 & 19,4 \\
\hline \multirow{6}{*}{$\begin{array}{c}\text { Chile } \\
\begin{array}{c}y=-, 157 \\
p=, 019\end{array}\end{array}$} & Materialista & 66,0 & 30,2 & 3,8 \\
\hline & 1 & 79,6 & 14,3 & 6,1 \\
\hline & 2 & 88,7 & 8,3 & 3,0 \\
\hline & 3 & 88,7 & 8,3 & 3,0 \\
\hline & 4 & 84,9 & 13,7 & 1,4 \\
\hline & Pós-materialista & 81,6 & 2,6 & 15,8 \\
\hline \multirow{6}{*}{$\begin{array}{l}\text { Peru } \\
y=, 275 \\
p=, 000\end{array}$} & Materialista & 96,8 & , 0 & 3,2 \\
\hline & 1 & 95,6 & 1,3 & 3,1 \\
\hline & 2 & 91,7 & 1,9 & 6,5 \\
\hline & 3 & 89,8 & 1,4 & 8,9 \\
\hline & 4 & 87,9 & 3,6 & 8,6 \\
\hline & Pós-materialista & 86,4 & 0 & 13,6 \\
\hline
\end{tabular}

Fonte: WORLD VALUES SURVEY OFFICIAL DATA FILE v.20081015, 2008. World Values Survey Association. 
No quadro geral dessas confirmações e refutações somos levados à conclusão de que a capacidade explicativa do índice de materialismo/pós. materialismo em relação à participação entre os públicos das nações investigadas é frágil. Como nosso tema central é a participação política, as duas modalidades fundamentais de atuação discutidas são os sindicatos e partidos políticos e justamente nesses dois casos o relacionamento não foi constatado.

Essa conclusão, entretanto, não questiona diretamente as hipóteses da teoria do desenvolvimento humano, pois como Inglehart e Welzel (2005) afirmam, a síndrome de valores pós-materialistas estaria muito mais relacionada ao crescimento das formas de participação política de tipo contestatória ou nãoconvencional ${ }^{12}$. Na próxima seção nos dedicamos a esses testes.

\section{Participação não convencional}

Como já destacado acima, seria justamente nas modalidades não convencionais de participação que os valores pós-materialistas estariam mais associados (INGLEHART, 2001; INGLEHART \& WELZEL, 2005).

$O$ interesse por essas modalidades de atuação tem como ponto de referência o estudo Political Action (BARNES et al, 1979) que teve o objetivo de verificar se as mudanças culturais intergeracionais e a elevação nos níveis de qualificação estavam impulsionando o surgimento de cidadãos mais ativos.

Dando continuidade a essas investigações, Inglehart (2001) comparou dados de 1981 e 1990 de 21 países e concluiu que tanto em termos de ação efetiva, quanto nas disposições para tal, ocorreu uma tendência de ampliação na adesão a essas práticas em escala mundial (Ibid.). Vejamos se essa mesma tendência se manifesta no contexto latinoamericano.

Assim como procedemos anteriormente, apresentamos os resultados e a sua evolução no período coberto pelas pesquisas do WVS. Começando pela participação por meio da assinatura de abaixo-assinados ou petições (Tabela 11), verificamos um quadro relativamente positivo, sobretudo se comparado com os níveis de envolvimento em organizações tradicionais estudados na seção anterior. 0 público brasileiro aparece aqui também como o mais propenso a esse tipo de ação, com mais da metade da amostra relatando que tem participado. Ao adicionarmos o percentual daqueles que escolheram a opção "poderia participar" temos mais de $83 \%$. O segundo país com maior número de praticantes é a Argentina, com 31,5\%

\footnotetext{
12 Norris (2007, p. 639), referindo-se a Barnes et al (1979), define a participação não convencional como sinônimo de protesto politico, que é definido como "as the willingness of citzens to engaje in dissent, including unofficial strikes, boycotts, petitions, the occupation of buildings, mass demonstrations, and even acts of political violence".
} 
afirmando que praticam e 35,6\% declarando que poderiam participar. Logo a seguir vem Peru e, por último o Chile.

Tabela 11

Participação em abaixo assinados por país, 2006

\begin{tabular}{|l|c|c|c|}
\hline & \multicolumn{3}{|c|}{ Abaixo-assinado } \\
\hline & $\begin{array}{c}\text { Nunca } \\
\text { participaria }\end{array}$ & $\begin{array}{c}\text { Poderia } \\
\text { participar }\end{array}$ & $\begin{array}{c}\text { Tem } \\
\text { participado }\end{array}$ \\
\hline Argentina & 32,9 & 35,6 & 31,5 \\
\hline Brasil & 16,9 & 27,6 & 55,5 \\
\hline Chile & 59,1 & 22,4 & 18,5 \\
\hline Peru & 37,4 & 37,9 & 24,8 \\
\hline
\end{tabular}

Fonte: WORLD VALUES SURVEY OFFICIAL DATA FILE v.20081015, 2008. World Values Survey Association.

As séries históricas de dados indicam certa tendência de ampliação nos percentuais em três dos países estudados. Em 1991, 22,4\% dos entrevistados argentinos selecionaram a opção "tem participado", em 1995 o percentual encontrado foi de $30,7 \%$ e em 2006 atinge 31,5 pontos. No Brasil, o percentual de $55 \%$ de 2006 representa uma elevação importante em comparação com os 47,1\% registrados em 1997. Entre os peruanos o percentual em 1996 era de 20,6\%, passou em 2001 para 22,4\% e atingiu em 24,8\% em 2006. Chile foi o único país que registrou trajetória decrescente, partindo de 22,9\% em 1990, caiu para $16,6 \%$ em 1996, subiu para 19,5\% em 2000 e em 2006 voltou a cair para 18,5\%.

o cruzamento dessa variável sobre atitudes participativas e o índice que mede a adesão aos valores pós-materialistas indica um cenário bastante diferente daquele observado na seção anterior. Em todos os quatro países verificamos coeficientes significativos e positivos, atingindo valores moderados, de 0,16 (Brasil) e 0,29 (Chile) (Tabela 12). Tais resultados confirmam a hipótese derivada da teoria do desenvolvimento humano de que indivíduos classificados como pós-materialistas tendem a manifestar com mais freqüência atitudes políticas contestadoras. 
Tabela 12

Assinatura de abaixo-assinado e pós-materialismo por país, 2006 (\%)

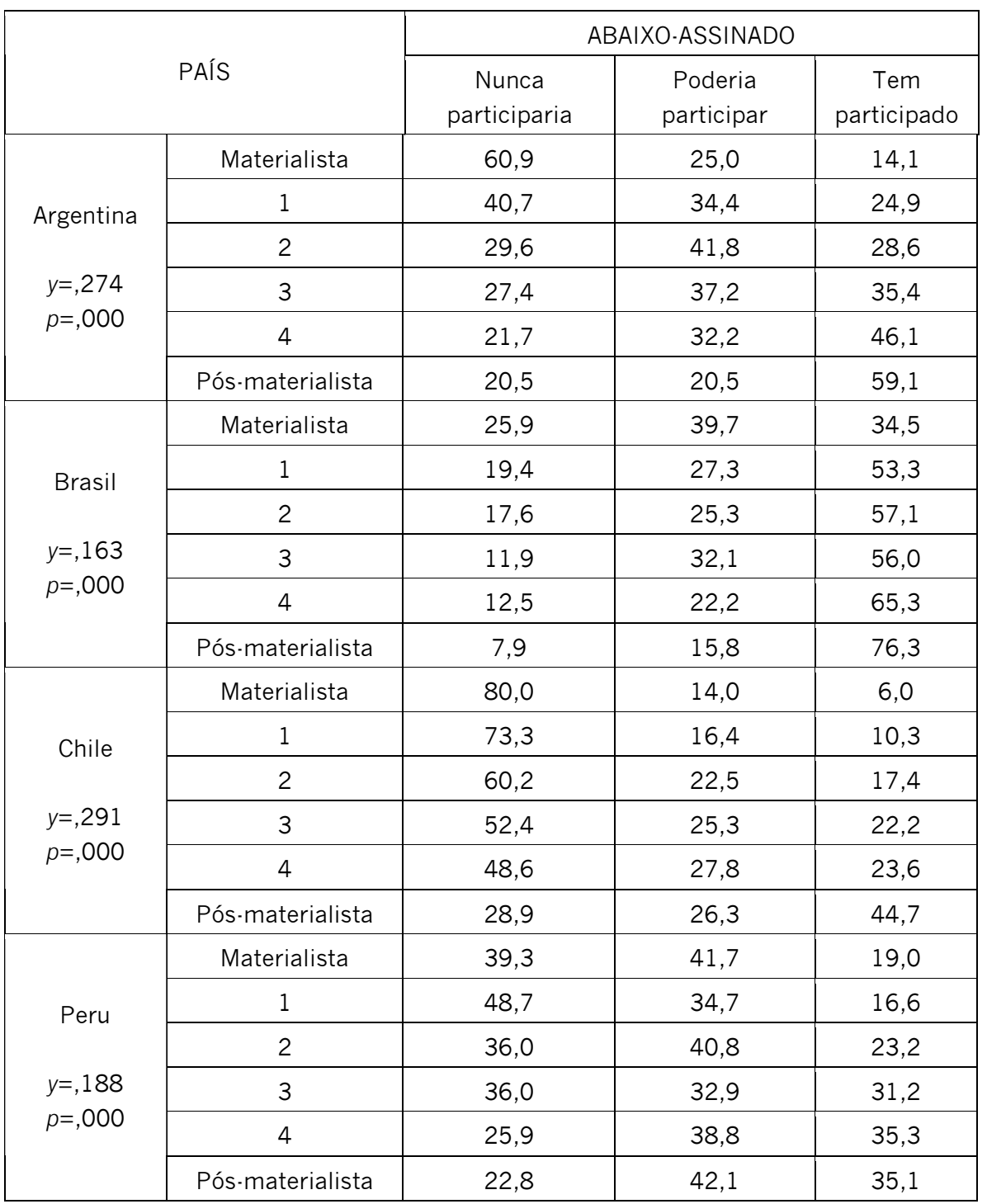

Fonte: WORLD VALUES SURVEY OFFICIAL DATA FILE v.20081015, 2008. World Values Survey Association.

No que diz respeito à participação em boicotes, entretanto, a situação não é tão positiva. Na realidade isso já era algo esperado, pois a assinatura de abaixo. assinados ou petições é uma ação que depende quase que exclusivamente da intenção individual, além de não envolver grandes volumes de recursos escassos, 
como tempo e dinheiro. Por outro lado, boicotes, passeatas e manifestações dependem de uma considerável organização e a participação exige algum investimento por parte dos cidadãos.

Como mostra a Tabela 13, essas diferenças se refletem nos percentuais de participação em boicotes entre os públicos dos quatro países analisados. O maior percentual é encontrado novamente entre os brasileiros, com 7,8\%. Na seqüência vem Peru (5,0\%), Argentina (3,4\%) e Chile (2,9\%).

Tabela 13

Participação em boicotes por país, 2006 (\%)

\begin{tabular}{|c|c|c|c|}
\hline & \multicolumn{3}{|c|}{ BOICOTE } \\
\hline PAÍs & $\begin{array}{c}\text { Nunca } \\
\text { participaria }\end{array}$ & $\begin{array}{c}\text { Poderia } \\
\text { participar }\end{array}$ & $\begin{array}{c}\text { Tem } \\
\text { participado }\end{array}$ \\
\hline Argentina & 80,3 & 16,3 & 3,4 \\
\hline Brasil & 66,8 & 25,3 & 7,8 \\
\hline Chile & 84,5 & 12,6 & 2,9 \\
\hline Peru & 70,2 & 24,8 & 5,0 \\
\hline
\end{tabular}

Fonte: WORLD VALUES SURVEY OFFICIAL DATA FILE v.20081015, 2008. World Values Survey Association.

Na série histórica, a Argentina descreve uma trajetória de ligeira elevação nesses valores, com 1,3\% em 1995 e 2,0\% em 199913. O mesmo ocorre no caso peruano que, em 1996, registrou 2,8\%. Brasil e Chile, inversamente, registraram reduções. No primeiro caso o WVS identificou 10,3\% em 1991 e 6,4\% em 1997. No segundo, em 1990 foram identificados 4\% e em 1996 2,3\%.

A Tabela 14 traz o cruzamento envolvendo essa modalidade de participação, bem como os coeficientes de associação encontrados. Em todas as quatro nações ocorreram associações estatisticamente significativas e os coeficientes foram de 0,10 a 0,24 , o que indica uma relação positiva entre aderir a uma postura pós. materialista e a disposição para participar de boicotes. Pós-materialistas e materialistas latinoamericanos se distinguiriam, portanto, em termos desse tipo de ação política não convencional.

13 Tal elevação pode estar associada à onda de protestos pelos quais passou a Argentina desde o final da década de 1990. Para uma cronologia dos fatos, ver Vitullo (2007). 
Tabela 14

Participação em boicotes e pós-materialismo por país, 2006 (\%)

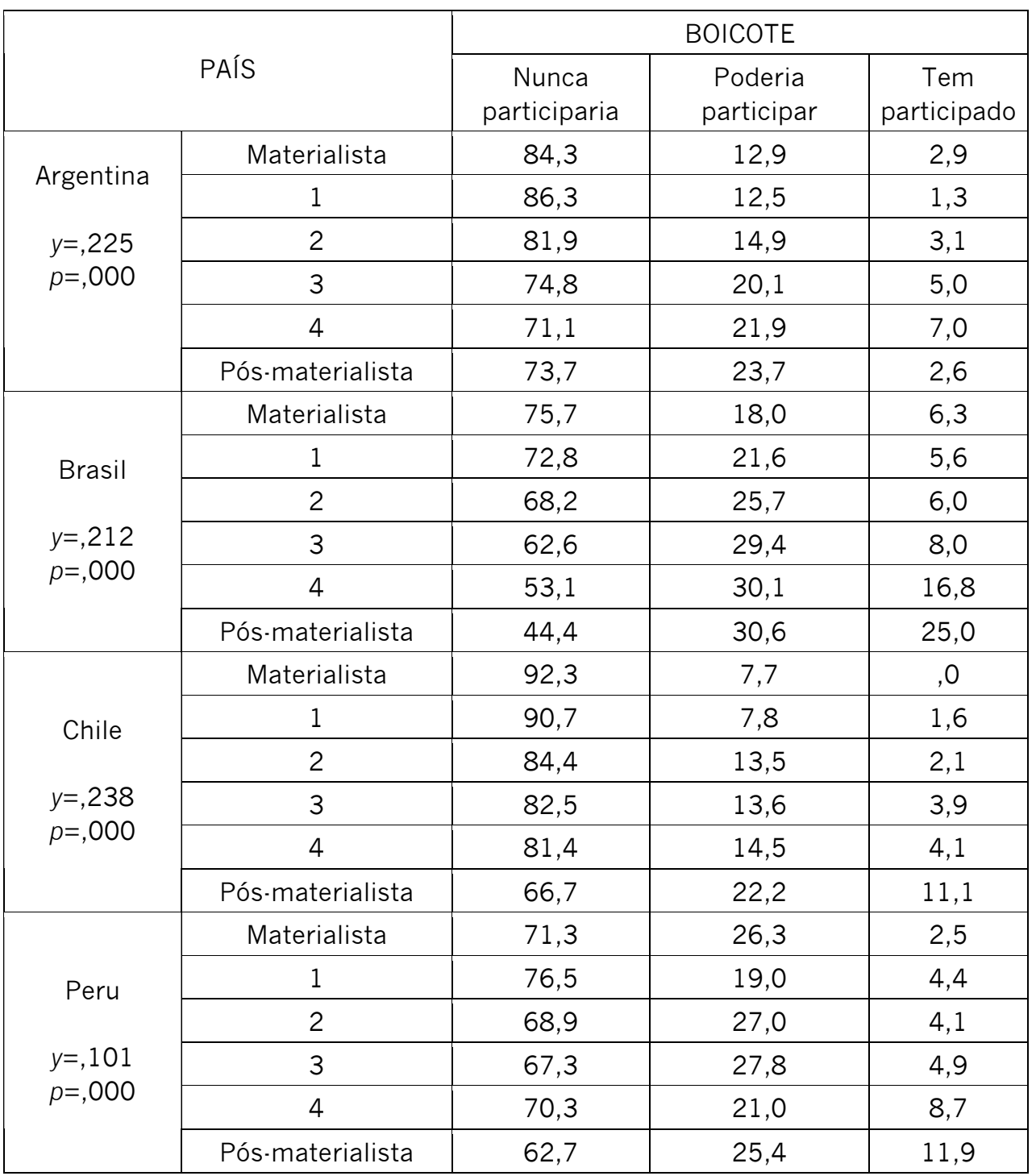

Fonte: WORLD VALUES SURVEY OFFICIAL DATA FILE v.20081015, 2008. World Values Survey Association.

Os dados sobre participação em passeatas ou manifestações pacíficas (Tabela 15) são relativamente mais positivos e revelam diferenças menos expressivas entre os públicos dos países. O Peru aparece como a nação com mais 
indivíduos que selecionaram a opção "tem participado" (24,2\%), seguido pela Argentina, com 20\%. Empatados com 18,2\% na seqüência aparecem Brasil e Chile.

Tabela 15

Participação em passeatas/manifestações por país, 2006 (\%)

\begin{tabular}{|c|c|c|c|}
\hline & \multicolumn{3}{|c|}{ PASSEATAS/MANIFESTAÇÕES } \\
\hline PAÍS & $\begin{array}{c}\text { Nunca } \\
\text { participaria }\end{array}$ & $\begin{array}{c}\text { Poderia } \\
\text { participar }\end{array}$ & $\begin{array}{c}\text { Tem } \\
\text { participado }\end{array}$ \\
\hline Argentina & 41,3 & 38,7 & 20,0 \\
\hline Brasil & 41,9 & 39,8 & 18,2 \\
\hline Chile & 60,2 & 21,6 & 18,2 \\
\hline Peru & 36,3 & 39,5 & 24,2 \\
\hline
\end{tabular}

Fonte: WORLD VALUES SURVEY OFFICIAL DATA FILE v.20081015, 2008. World Values Survey Association.

Em termos históricos, podemos identificar na Argentina uma tendência de recuperação nesse tipo de ação, uma vez que em 1995 foram verificados 16,3\% e $13,3 \%$ em 1999. No Peru, a elevação também ocorreu, passando de 12,2 pontos percentuais em 1996, para $17 \%$ em 2001. Apesar de mais sutil, no Chile encontramos esse mesmo movimento, passando de 14,8\% em 1996 para 15,7\% em 2000 e chegando em 2006 com 18,2 pontos. O Brasil, novamente, demonstra tendência contrária, com redução no contingente de participantes. Em 1997 24,8\% dos entrevistados brasileiros optaram pela alternativa "tem participado", ou seja, mais de 6 pontos acima do que a pesquisa mais recente registrou.

As associações os resultados são favoráveis às hipóteses derivadas da teoria do desenvolvimento, pois todos os coeficientes foram significativos e positivos. A ordem dos resultados encontrados é parecida com a do teste anterior, com a maior intensidade de relacionamento encontrada entre os chilenos $(0,32)$, a segunda maior entre os argentinos $(0,24)$, seguidos pelos brasileiros $(0,18)$ e, por fim, peruanos $(0,15)$. 
Tabela 16

Participação em passeatas/manifestações

e pós-materialismo por país, 2006 (\%)

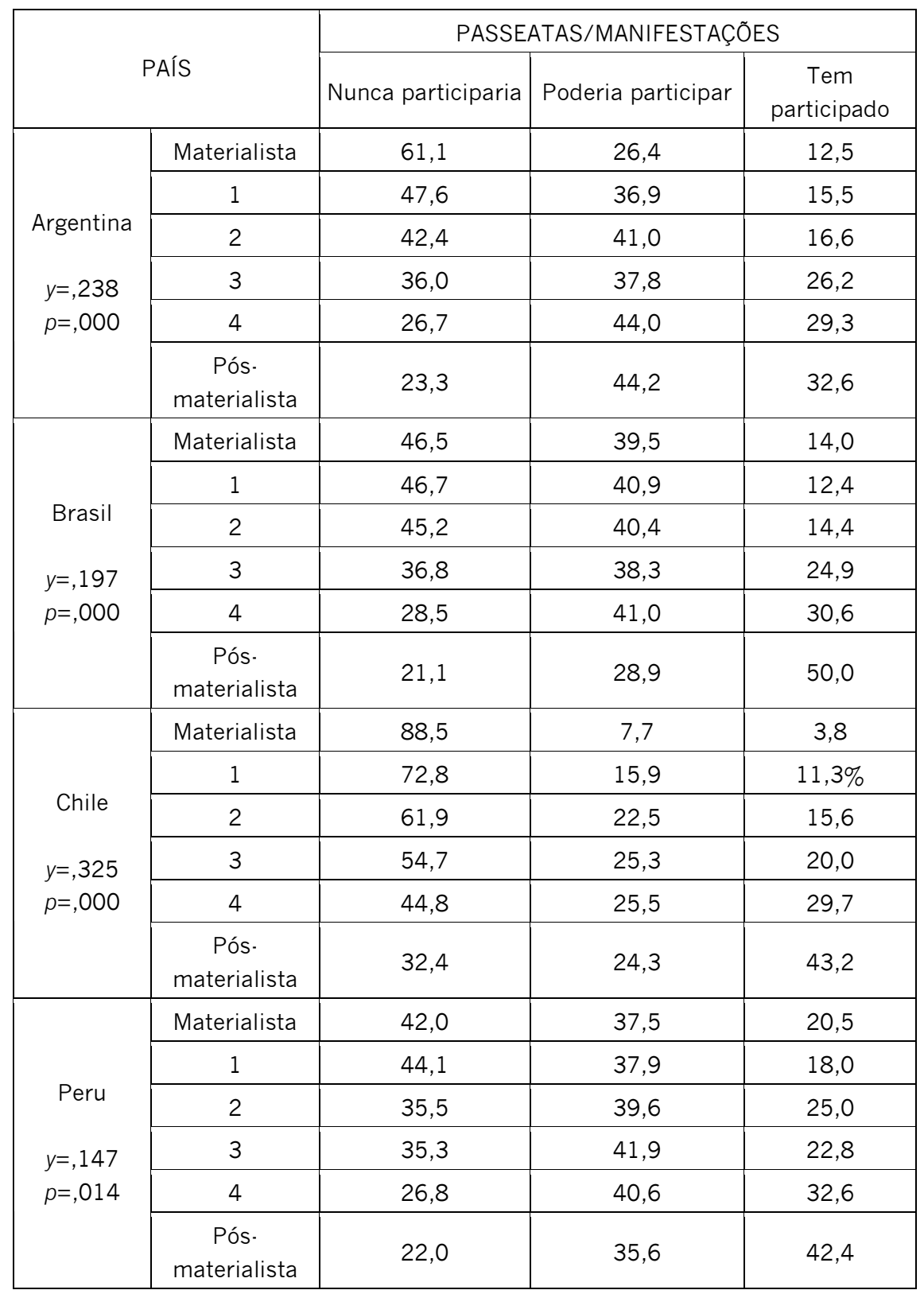

Fonte: WORLD VALUES SURVEY OFFICIAL DATA FILE v.20081015, 2008. World Values Survey Association. 
A consistência desses resultados, todavia, precisa ser avaliada à luz de análises de regressão que introduzam variáveis relevantes como sexo e escolaridade, assim como fizemos no caso do interesse por política. Como aqui se tratam de várias medidas de participação, para ocupar a posição de variável dependente construímos um índice de participação a partir do somatório das respostas dos entrevistados às três modalidades de ação não convencional ${ }^{14}$.

Tabela 17

Análise fatorial das quatro variáveis de ação não convencional por país

\begin{tabular}{|l|c|c|c|c|}
\hline \multirow{2}{*}{ ORGANIZAÇÃO } & \multicolumn{4}{|c|}{ PAÍs } \\
\cline { 2 - 5 } & Argentina & Brasil & Chile & Peru \\
\hline Abaixo-assinados &, 835 &, 722 &, 855 &, 781 \\
\hline Boicotes &, 661 &, 742 &, 750 &, 708 \\
\hline Passeatas/manifestações &, 862 &, 806 &, 836 &, 758 \\
\hline$\%$ de variação explicada por 1 fator & 62,57 & 57,42 & 66,41 & 56,17 \\
\hline
\end{tabular}

Fonte: WORLD VALUES SURVEY OFFICIAL DATA FILE v.20081015, 2008. World Values Survey Association.

Como mostra a Tabela 18 , os resultados do modelo multivariado se não refutam a hipótese do efeito positivo da síndrome de valores pós-materialistas sobre essa forma de participação não-convencional, revelam a fragilidade da sua capacidade explicativa.

\footnotetext{
${ }^{14}$ A redução dessas variáveis a uma única medida integrada foi efetuada após a realização de análise fatorial que indicou a pertinência desse procedimento uma vez que apenas um único fator foi capaz de explicar mais de $62 \%$ da variação conjunta das medidas originais.
} 
Tabela 18

Preditores da participação não-convencional, 2006

\begin{tabular}{|c|c|c|c|c|}
\hline PAÍS & & B & Beta & $p$ \\
\hline \multirow{5}{*}{ Argentina $^{1}$} & Índice de materialismo/pós-materialismo &, 214 &, 163 &, 000 \\
\hline & Escolaridade &, 378 &, 311 & ,000 \\
\hline & Sexo & $\cdot, 021$ & $\cdot, 006$ & ,847 \\
\hline & Classe social (subjetiva) & ,022 & ,011 & ,764 \\
\hline & Idade & $\cdot, 003$ & $\cdot, 028$ & ,411 \\
\hline \multirow{6}{*}{ Brasil } & Índice de materialismo/pós-materialismo &, 172 &, 124 & ,000 \\
\hline & Escolaridade & ,315 & ,334 & ,000 \\
\hline & Sexo & ,254 & ,078 &, 002 \\
\hline & Classe social (subjetiva) & $\cdot, 018$ & $\cdot, 010$ & ,726 \\
\hline & Renda & $\cdot, 028$ & $\cdot, 038$ &, 175 \\
\hline & Idade & $\cdot, 003$ & $\cdot, 029$ & ,252 \\
\hline \multirow{6}{*}{ Chile } & Índice de materialismo/pós-materialismo & ,299 & ,214 & ,000 \\
\hline & Escolaridade &, 228 & ,202 &, 000 \\
\hline & Sexo & ,352 &, 105 & ,001 \\
\hline & Classe social (subjetiva) &, 121 & ,066 &, 104 \\
\hline & Renda & $\cdot, 064$ & $\cdot, 072$ & ,072 \\
\hline & Idade & $\cdot, 004$ & $\cdot, 036$ & ,313 \\
\hline \multirow{6}{*}{ Peru } & Índice de materialismo/pós-materialismo & ,116 & ,083 & ,003 \\
\hline & Escolaridade & ,222 & ,208 & ,000 \\
\hline & Sexo &, 355 &, 111 & ,000 \\
\hline & Classe social (subjetiva) & ,039 & ,021 &, 474 \\
\hline & Renda & ,080 & ,084 & ,010 \\
\hline & Idade & ,006 &, 057 &, 040 \\
\hline
\end{tabular}

Notas: 1) Não existem dados sobre renda para a Argentina, desta forma seu modelo envolve apenas cinco variáveis;

2) $\mathrm{R}^{2}$ Ajustado: Argentina= ,150; Brasil=,149; Chile=,125; Peru=,106;

3) Método Enter.

Fonte: WORLD VALUES SURVEY OFFICIAL DATA FILE v.20081015, 2008. World Values Survey Association. 
Com exceção do caso chileno, em todos os países o referido índice de 12 itens apresentou efeito menor do que a escolaridade ${ }^{15}$, apesar de produzir impactos com nível de significância aceitável. O nível de escolaridade dos entrevistados se mostrou mais relevante na explicação da ocorrência de atitudes participativas entre argentinos, brasileiros e peruanos. Em três dos quatro países, excetuando-se Argentina, a variável sexo se mostrou relevante, sendo que entre peruanos o seu efeito foi maior do que o produzido pelo índice de pós-materialismo. As demais variáveis incluídas no modelo não produziram efeitos consideráveis em termos gerais, mas é preciso mencionar que no caso peruano a renda e a idade dos entrevistados apresentaram efeitos estatisticamente significativos. Um dado que merece nossa atenção diz respeito à idade dos indivíduos, que entre argentinos, brasileiros e chilenos não afetou o nível de participação contestatória. Nossa suposição inicial era de que os membros de grupos etários mais jovens seriam mais propensos a adotarem tais modalidades de ação política, entretanto, as análises demonstraram que não existe variação considerável em termos geracionais.

Em termos gerais, assim como no caso do interesse por política, no cenário latinoamericano, a educação parece ser uma variável mais eficaz na explicação da ocorrência de uma postura participativa.

\section{Conclusão}

Os dados analisados parecem apontar para a reduzida capacidade explicativa de hipóteses derivadas da teoria do desenvolvimento humano para o nível individual quando o assunto são as modalidades de participação política entre brasileiros, argentinos, peruanos e chilenos. Os testes de associação envolvendo tipos de participação convencional e o índice de materialismo/pós-materialismo indicaram a existência de independência. Esse resultado contraria a hipótese defendida por Inglehart e seus colaboradores que afirma a existência de um relacionamento negativo, ou seja, quanto mais pós-materialista menor seria a probabilidade de envolvimento nessas formas tradicionais. Mas a principal limitação da teoria diz respeito ao interesse por política e, sobretudo, as formas de participação não convencionais ou contestatórias. Para a quase totalidade (com exceção do Chile para a participação não convencional) dos casos analisados, a

\footnotetext{
${ }^{15}$ Assim como no caso do modelo sobre interesse, preocupados com o problema da colinearidade entre educação e pós-materialismo, conduzimos os testes de Tolerância e VIF, não encontrando valores preocupantes (abaixo de 0,10 e acima de 5, respectivamente para cada teste) em nenhuma das duas variáveis nos quatro países.
} 
escolaridade do entrevistado teve peso mais significativo do que a escala de materialismo/pós-materialismo. Nesse sentido, como já destacado anteriormente, os dados parecem corroborar as hipóteses derivadas do modelo da centralidade.

Em termos de explicação teórica para tais achados empíricos, vale introduzir brevemente as reflexões de Fábio W. Reis (2000). Referindo-se ao problema da participação política no Brasil, escreve: “(...) a proposição básica é a de que os fatores correspondentes às diferentes dimensões da noção de centralidade exercem um papel causal não apenas diretamente com respeito à participação política (...) mas também ao condicionarem, em ampla medida, as probabilidades de que o modelo da consciência de classe possa ele próprio atuar sobre aquela participação" (p. 263). Na perspectiva de Reis, fatores associados à centralidade forneceriam um "limiar de participação" (p. 264), na base do qual poderiam operar os elementos ligados ao contexto em que os indivíduos estão inseridos e que conformariam sua identidade. Além do mais, a dimensão da centralidade estaria associada ao plano cognitivo do indivíduo e sua capacidade ou não de interpretar de forma coerente o mundo político (p. 274).

As relações entre tal proposição e os dados apresentados no presente texto fornecem elementos para explorar algumas hipóteses sobre o porquê, nos países em estudo, o engajamento do indivíduo em formas não convencionais, seja mais uma função da escolaridade do indivíduo do que do fato de ser "pós-materialista". Nesse sentido, parece que a escolaridade, vista como uma medida de centralidade, ofereceria um "limiar" para a operação seja do "interesse por política", seja para a difusão das formas "contestatórias de participação", sem a necessidade da intermediação dos valores pós-materialistas.

\section{Referências Bibliográficas}

ALMOND, G. \& VERBA, S. The Civic Culture: political attitudes and democracy in five nations. New York: Sage, 1969.

AVELAR, L. Participação política. In: AVELAR, L. \& CINTRA, A. O sistema político brasileiro: uma introdução. Rio de Janeiro: Fundação Konrad Adenauer, 2004. 
BARNES, S. et al. Political Action: mass participation in five western democracies. Beverly Hills: Sage Publications. 1979.

BOHRNSTEDT, G.G. \& KNOKE, D. Statistics for Social Data Analysis. New York: Peacock, 1982.

BORBA, J. Cultura política e capital social na América do Sul. In: BAQUERO, M. (Org.). Capital social, desenvolvimento sustentável e democracia na América Latina. Porto Alegre: Editora da UFRGS, 2007.

CARRIÓN, J. F., ZÁRATE, P. 2008. Cultura política de la democracia en el Perú, 2008. El impacto de la governabilidad. LAPOP [Online] Disponível em:

<http://sitemason.vanderbilt.edu/files/

bU2m Ji/Resumen\%20ejecutivo\%20Cultura\%20politica\%20de\%20la\%20democraci a\%20en\%20el\%20Peru\%202008.pdf> Acesso em: [mar. 2010].

CASTRO, H. C. O. Democracia e mudanças econômicas no Brasil, Argentina e Chile: um estudo comparativo de cultura política. Tese (Doutorado em Ciência Política), Porto Alegre, UFRGS, 2000.

DELLAPORTA, D. Paths to February 15 protest: social or political determinants? [Online] Disponível em:

<www.Ise.ac.uk/Deps/global/PDFs/Peaceconference/dellaporta.doc> Acesso em: [dez. 2008].

GIBSON, J.L.; DUCH, R.M. Postmaterialism and the emerging soviet democracy. Political Research Quarterly, n.47, p.5-39, 1994.

HOFFMANN, R. Distribuição de renda: medidas de desigualdade e pobreza. São Paulo: Edusp, 1998.

INGLEHART, R. The Silent Revolution. Princeton: Princeton University Press, 1977. Press, 1990

Culture shift in advanced industrial society. Princeton: Princeton University

Postmodernization, authority, and democracy. In: NORRIS, P. (org.). Democratic Phoenix: political activism worldwide, Cambridge: Cambridge University Press, 1999.

Modernización y posmodernización: el cambio cultural, económico y político en 43 sociedades. Madrid: Centro de Investigaciones Sociológicas/Siglo Veintiuno, 2001.

INGLEHART, R. \& WELZEL, C. Modernization, cultural change, and democracy: the human development sequence, New York: Cambridge University Press, 2005. 
KRISCHKE, P. J. D. S. Aprendendo a democracia na América Latina: atores sociais e mudança cultural. Porto Alegre: Edipucrs, 2003.

LAPOP. 2008. Presentación de resultados. Encuesta LAPOP 2008. Chile. Disponível em <http://sitemason.vanderbilt.edu/lapop/ CHILEBACK> Acesso em: [mar. 2010].

MILBRATH, L.; GOEL, M.L. Political participation. Boston: University Press of America, 1965.

NORRIS, P. Critical Citizens: global support for democratic government. Oxford: Oxford University Press, 1999.

Democratic Phoenix: political activism worldwide. Cambridge: Cambridge University Press, 2002.

Political activism: new challenges, new opportunities. In: BOIX, C. \& STOKES, S. The Oxford Handbook of Comparative Politics [Online] Oxford: Oxford University Press, 2007. Disponível em <http://ksghome.harvard.edu/ pnorris/Acrobat/Boix\&stokes-chap26.pdf.> Acesso em: [fev. 2009].

O'BRIEN, R. M. A caution regarding rule of thumb for variance inflation factors. Quality and Quantity, n. 41: 673-90, 2007.

OPP, K. Postmaterialism, collective action, and political protest. American Journal of Political Science, n.34, p. 212-35, 1990.

PIZZORNO, A. Introduccion al estúdio de La participacion política. In: PIZZORNO, A.; KAPLAN, M.; CASTELLS, M. Participación y cambio social em lá problemática contemporânea. Buenos Aires: SIAP, 1975.

REIS, F. W. Mercado e utopia: teoria política e sociedade brasileira. São Paulo: Edusp. 2000.

RIBEIRO, E.A. Cultura política, instituições e experiência democrática no Brasil. Revista de Sociologia e Política, Curitiba, n. 28, p. 205-219, jun. 2007.

. Valores pós-materialistas e cultura política no Brasil. Tese (Doutorado em Sociologia), Curitiba, UFPR, 2008.

VALDIVIESO, P. Capital social e desenvolvimento democrático: Porto Alegre (Brasil) e Santiago do Chile. Revista Brasileira de Ciências Sociais, v.24, n.69, p.93.114, 2009. 
VERBA, S. \& NIE, N.H. Participation in América. Political democracy and social equality. New York: Harper \& How, 1972.

VERBA, S.; SCHLOZMAN, K.L.; BRADY, H.E. Voice and equality. Civic voluntarism in American politics. Cambridge: Harvard University Press, 1995.

VITULLO, G. Teorias da democratização e democracia na Argentina. Porto Alegre:

Sulina. Natal: Ed. UFRN, 2007.

Ednaldo Aparecido Ribeiro - ednaldorip@uol.com.br

Julian Borba·julian@cfh.ufsc.br

Recebido para publicação em setembro de 2009.

Aprovado para publicação em fevereiro de 2010. 